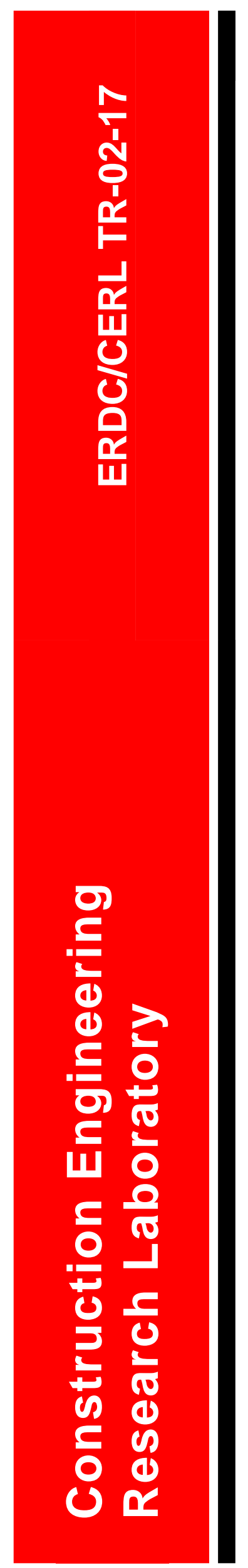

\title{
Assessment of Effects of Maneuver Training Activities on Red-cockaded Woodpecker Populations on Fort Stewart, GA
}

Timothy J. Hayden, Robert H. Melton, Beth Willis,

L.B. Martin III, and Tim Beaty

August 2002

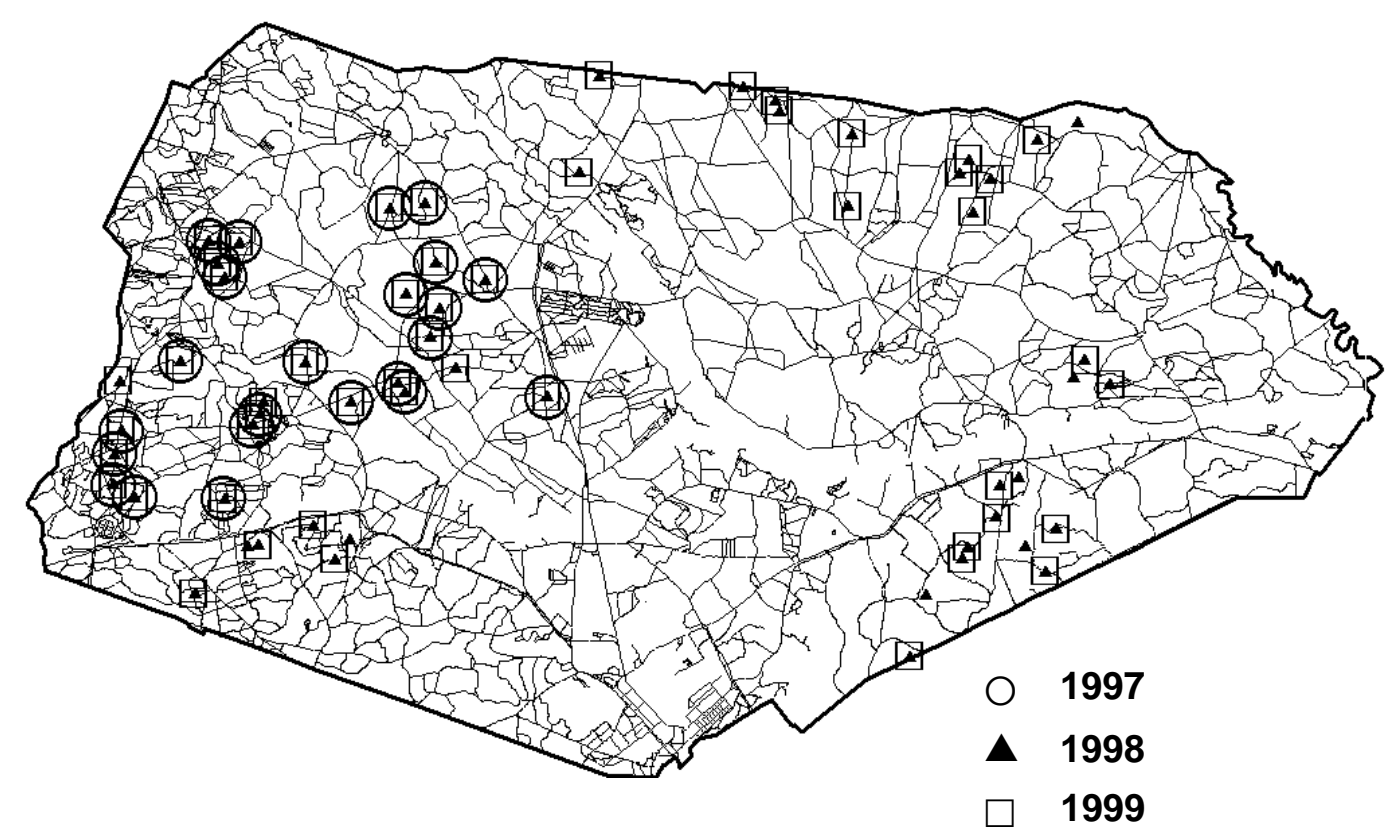




\section{Foreword}

This study was conducted for Headquarters, Department of the Army, Assistant Chief of Staff (Installations Management) (ACS(IM)) under 62720A896, "Environmental Quality Technology," Work Unit TD0, "Threshold I mpact of Maneuver Training." The technical monitor was Dr. Victor Diersing, DAIM-ED-N.

The work was performed by the Ecological Processes Branch CN-N of the Installation Division $(\mathrm{CN})$, Construction Engineering Research Laboratory (CERL). The CERL Principal Investigator was Timothy J . Hayden. Robert $\mathrm{H}$. Melton is a researcher employed by CERL. Beth Willis and Tim Beaty are employed by the DPW, Fish and Wildlife Branch at Fort Stewart, GA. L.B. Martin III is employed by the Department of Ecology and Evolutionary Biology at Princeton University, Princeton, NJ . The technical editor was Gloria J . Wienke, Information Technology Laboratory. Steve Hodapp is Chief, CEERD-CN-N, and Dr. J ohn T. Bandy is Chief, CEERD-CN. The associated Technical Director was Dr. William D. Severinghaus, CEERD-CV-T. The Acting Director of CERL is Dr. Alan W. Moore.

CERL is an element of the U.S. Army Engineer Research and Development Center (ERDC), U.S. Army Corps of Engineers. The Commander and Executive Director of ERDC is COL J ohn W. Morris III, EN and the Director of ERDC is Dr. $\mathrm{J}$ ames R. Houston.

DISCLAIMER: The contents of this report are not to be used for advertising, publication, or promotional purposes. Citation of trade names does not constitute an official endorsement or approval of the use of such commercial products. All product names and trademarks cited are the property of their respective owners. The findings of this report are not to be construed as an official Department of the Army position unless so designated by other authorized documents.

DESTROY THIS REPORT WHEN IT IS NO LONGER NEEDED. DO NOT RETURN IT TO THE ORIGINATOR. 


\section{Contents}

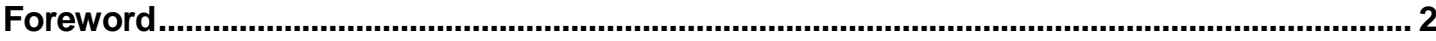

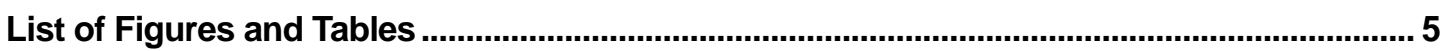

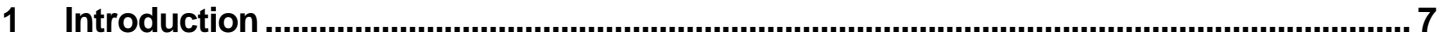

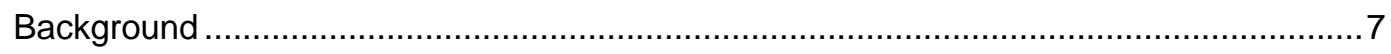

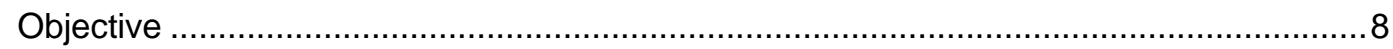

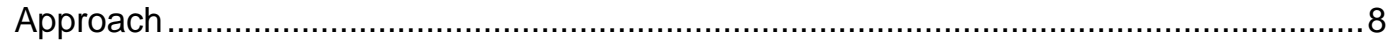

Scope

Mode of Technology Transfer .................................................................................

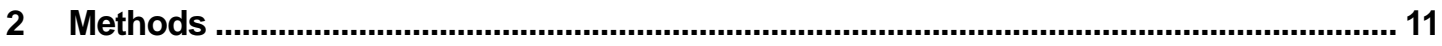

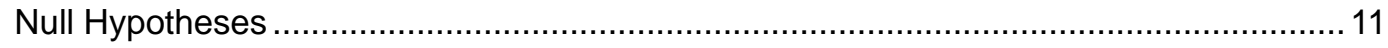

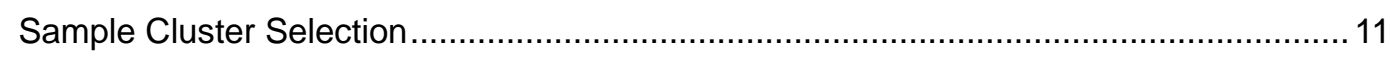

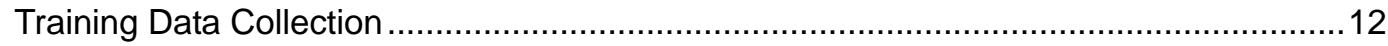

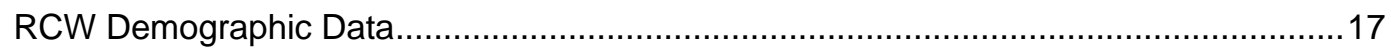

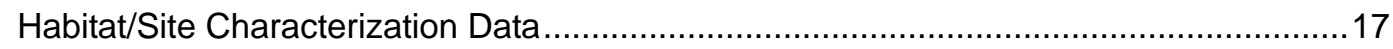

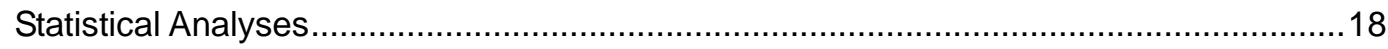

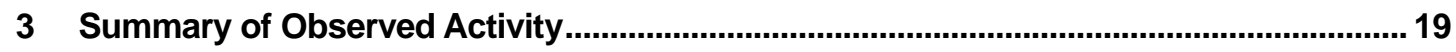

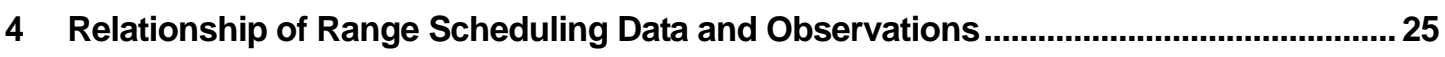

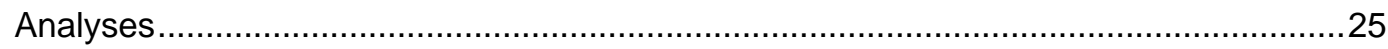

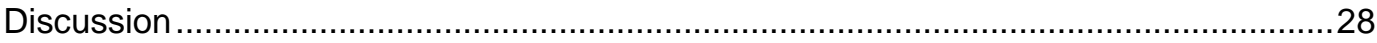

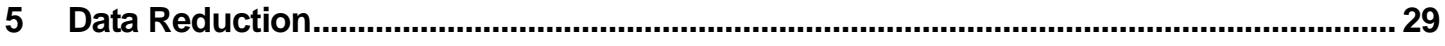

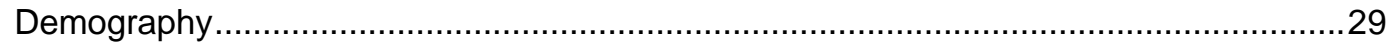

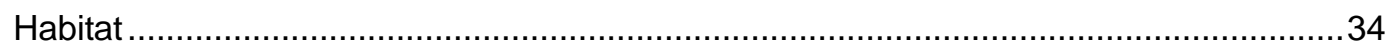

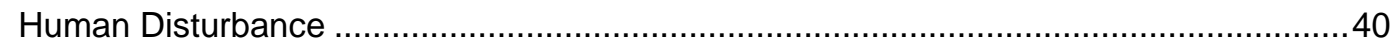

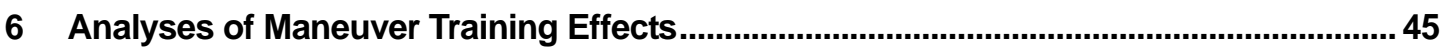

7 Determining Population Level Effects of Military Disturbance ......................................... 49

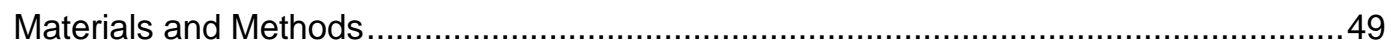

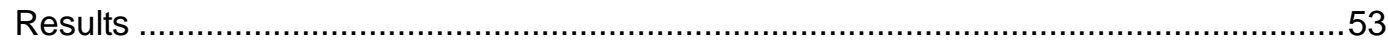

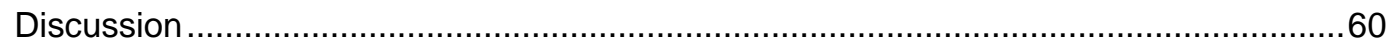




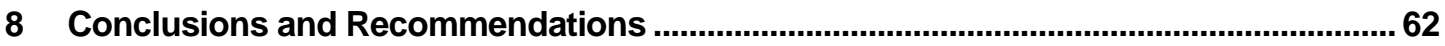

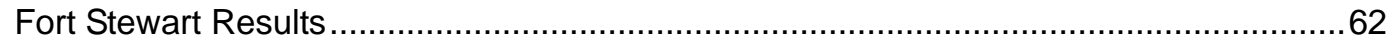

Use in Endangered Species Risk Assessments ....................................................64

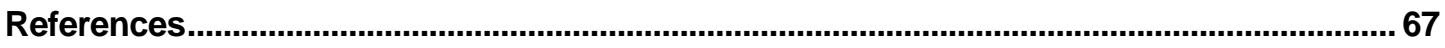

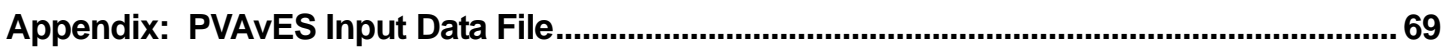

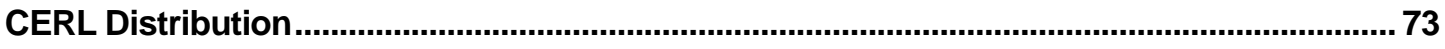

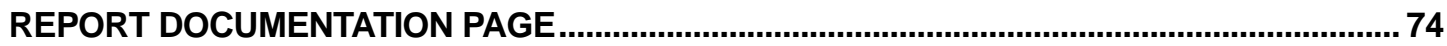




\section{List of Figures and Tables}

\section{Figures}

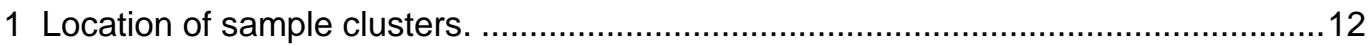

2 Relative frequency of vehicle type observed during 10-minute sample

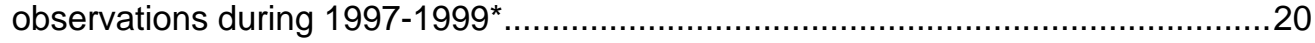

3 Mean proportion of 10-minute sample observations in which military activity was observed during 1997-1999.

4 Proportion of observed total human activity during 10-minute sample observations during 1997-1999.

5 Proportion of observed military activity during 10-minute sample observations during 1997-1999.

6 Proportion of observed total human activity during 10-minute sample observations during 1997-99....

7 Histograms for analysis of 1998 data.

8 Mean number of fledged by year, grouped by independent variables.

9 Ordination of RCW clusters along first three principal components of measured habitat variables.

10 Mean number of young fledged by year, grouped by SITELOAD

11 Mean number of young fledged by year, grouped by ROAD(CLASS).

12 Classification of Red-cockaded Woodpecker clusters used in the population viability analysis, based on 2- or 3-year mean levels of military and civilian activity.

13 Estimated pseudoextinction probabilities for the Red-cockaded Woodpecker population on Fort Stewart.

14 Estimated probabilities that the Red-cockaded Woodpecker population on Fort Stewart should be classified as vulnerable, endangered, and critical.

Tables

1 Description and coding for variables included for analyses or data collected on Fort Stewart, Georgia in 1997-1999.

2 Observed vehicle types during 10-minute sample observations, 1997-1999.

3 Average percentage of 10-minute observation periods with observed events per monitored cluster.

4 Events of human activity observed in proximity to RCW clusters. 
5 Spearman rank correlation matrix for military training variables and cluster proximity to roads 26

6 Non-parametric means test for NFLDG grouped by demographic variables 32

7 Significance values for Fisher's exact test of independence between dependent variables (rows) and independent variables (columns) 1997-1999.

8 Critical values from principal component analysis of RCW cluster habitat variables.

9 Correlation coefficients of PCA scores and measured RCW cluster habitat variables after varimax rotation.

10 Spearman rank correlation coefficients between principal components scores of measured habitat variables and number of useable RCW cavities in 1998 and number of fledglings produced by cluster for years 1997, 1998, and 1999.

11 Critical values (Wald statistic $(W)$ and $P$-value $(P)$ ) from logistic regression analyses of principal component scores of habitat variables and number of useable RCW cavities in 1998 and binomial measures of RCW reproductive success in the years 1997-1999.

12 Spearman rank correlation matrix for potential disturbance variables and number of young fledged, 1997-99.

13 Non-parametric means test for NFLDG grouped by SITELOAD and ROAD (CLASS)

14 Logistic regression statistics.

15 Results of multiple linear regression for NFLDG for all independent variables entered as model terms.

16 Comparison of relative significance of regression coefficients of independent variables in stepwise regression (GLM) for number of young fledged.

17 Comparison between complete multivariate regression model $(G L M)^{*}$ results for NFLDG with all possible submodels with two independent variables.

18 Nest productivity summary statistics, over three years, for Red-cockaded Woodpecker clusters in "low" and "high" disturbance activity classes.

19 Estimated PVAvES nest productivity parameters, calculated from the RCW clusters in "low" and "high" disturbance activity classes.

20 Parameterization of nine hypothetical disturbance scenarios, derived as weighted averages of the parameter estimates in Table 19. 


\section{Introduction}

\section{Background}

Numerous U.S. military installations provide habitat for significant populations of F ederally listed threatened and endangered species. In a 1998 survey of Army installations, 95 installations reported on-site occurrence of F ederally listed species (Schreiber and Reed 1999). The potential conflicts between compliance with the Endangered Species Act of 1973, as amended (ESA) and the Army's mission to train and prepare soldiers for military conflict, places a significant burden on the Army to evaluate effects of its mission activities on endangered species occurring on installation lands and to support recovery of endangered populations. Efforts to resolve conflicts between endangered species protection and recovery and the Army's training requirements have often been hampered by a lack of knowledge of the potential effects of military training activities on endangered species (Gutzwiller and Hayden 1997, Hayden 1997). Without this information the U.S. Fish and Wildlife Service (USFWS), which is the agency for federal regulatory actions under the ESA, can elect to place conservative restrictions on military training activities to meet the mandate for protection and recovery of endangered species populations and habitats. The negative impact of restrictions on unit readiness due to the presence of endangered species was highlighted by the Army's testimony before the U.S. Senate's Environment and Public Works Committee during hearings in 1995 (Hayden 1997).

As a result of increasing conflicts between endangered species occurrence and training and increasing demand for information on the actual effects of training on endangered species populations and habitats, the U.S. Army Corps of Engineers (USACE) initiated research in fiscal year 1996 under the USACE directfunded research program to evaluate effects of maneuver training on endangered species. Concurrent with the beginning of this research initiative, the Army initiated a revision of the Army management guidelines for the red-cockaded woodpecker (Picoides borealis, RCW) on Army installations. This species occurs on seven Army installations, including three major Forces Command (FORSCOM) and two major Training and Doctrine Command (TRADOC) installations. Training restrictions on these installations were the impetus for revision of the Army management guidelines to reduce restrictions on training while enhancing recovery activities for the RCW. However, knowledge of the effects of maneuver 
training on RCWs was lacking, and the USFWS required the Army to implement a research program to evaluate training effects on RCWs. The USFWS documented this requirement in its October 1996 opinion for implementing the revised Army guidelines. This requirement under the USFWS October biological opinion provided the focus for the USACE direct-funded research to evaluate effects of maneuver training activities on the RCW.

In early 1997 a draft research plan was submitted to USFWS for peer review of a study to evaluate effects of military training on RCWs on Fort Stewart, GA, that would meet, in part, requirements for implementing the revised Army management guidelines for RCWs. This plan (Hayden 1999) outlined a research approach to evaluate the relative effects of military training, habitat, and demographic parameters on critical RCW population parameters. The report documents the results of these studies performed during the years 1997, 1998, and 1999.

\section{Objective}

The purpose of this research is to evaluate effects of military maneuver training activities on RCW populations on Fort Stewart, GA, and based on these research results to provide recommendations to the Army for monitoring and assessment of training effects on endangered species.

\section{Approach}

Hayden (1999) discusses study design considerations and limitations for this research effort. A primary challenge in evaluating potential impacts of maneuver training on RCW populations and habitats is characterizing and quantifying maneuver training in an environmental context. "Maneuver training" is not a specific entity that can be easily quantified and described. It is a complex interaction of events, participants, and equipment that is highly dynamic and variable both spatially and temporally. Another major challenge of any study implemented at the landscape scale is quantifying the temporal, spatial, and stochastic variability of the natural system under consideration.

The high degree of dynamic variability both in the natural system (RCW populations and habitats) and the factors (maneuver training and RCW management) potentially affecting these systems presents several difficulties in developing approaches to evaluate potential impacts of maneuver training on populations or habitats. First, the spatial and temporal variability of maneuver training as it is 
conducted under actual conditions has not been well documented and currently cannot be easily predicted at the site-specific level - there is no baseline data to establish experimental levels for training that reflect predicted or anticipated levels of training activity. Second, given the inherent complexity in the characteristics of maneuver training, extreme care must be given to constructing appropriate hypotheses that can be evaluated given the complexity of the system and factors under consideration. Third, results of any observed effects at the site-specific or individual level must be evaluated in the context of population effects.

Data necessary to address these research complexities and to test established hypotheses can be derived from either of two fundamental research approaches: experimental designs or observational studies. Hayden (1999) discusses several factors that preclude controlled experimental designs to evaluate hypotheses specified in this study. Limitations in implementing an experiment are due primarily to the complexity of mission activities related to maneuver training. Due to the factors discussed in Hayden (1999), the current study relies on observational data to evaluate effects of training on RCW populations on Fort Stewart. Data collection and analyses emphasize three major areas of investigation:

- Characterizing maneuver training activities in relation to RCW populations and habitats.

- Evaluating effects of maneuver training activities on critical RCW population parameters in relation to other habitat and demographic variables affecting RCW populations.

- Evaluating observed or potential effects of training at the population level.

This report first documents research methods and analytical approaches in Chapter 2. Chapter 3 provides data summaries for observations of maneuver training activities in proximity to RCW clusters and Chapter 4 evaluates military scheduling data as a predictor of site-specific training activities. Chapters 5 and 6 report the results for field studies conducted on Fort Stewart during 19971999 to assess effects of training on RCW populations. Chapter 7 demonstrates application of results from field studies to evaluate extinction risk and recovery probability. Chapter 8 reports conclusions from research on Fort Stewart and discusses applications for generalized approaches to assessment of training effects on endangered species and military installations. 


\section{Scope}

This report documents research results for field studies conducted on Fort Stewart, GA, during 1997-1999. Conclusions of this report based on empirical observations specific to data collected on Fort Stewart should not be extrapolated to other locations. General research and analytical approaches and applications of empirical models may be applied to assessment of military training effects in other locations and contexts.

\section{Mode of Technology Transfer}

This report will be made accessible through the World Wide Web (WWW) at URL:

http://www.cecer.army.mil 


\section{Methods}

Based on the research design considerations discussed in Chapter 1 and Hayden (1999), the approach for this research relied primarily on observational data to investigate the relationship of maneuver training activities and RCW demographic parameters. The null hypotheses outlined here are formulated based on the availability of observational data to test measures of association. This approach in general will not establish cause-and-effect relationships between maneuver training activity and RCW demographic and habitat parameters. However, this approach is designed to provide adequate information to make informed evaluations and decisions regarding the associations of training activity and RCW populations relative to effects attributable to habitat and demographic factors. This chapter revises proposed methods for this research described by Hayden (1999).

\section{Null Hypotheses}

The following generalized null hypotheses $(\mathrm{H} 0)$ guided data collection, summary, and statistical analyses to characterize maneuver training activity in RCW dusters and evaluate relationships between maneuver training activity and RCW populations and habitats.

- No relationship exists between levels of training activity indicated from range scheduling data and observations of training activity at cluster sites.

- No relationship exists between RCW demographic parameters and maneuver training activity on Fort Stewart, GA, during 1997-1999.

These general hypotheses are further specified as statistical tests presented in Chapters 3 through 6.

\section{Sample Cluster Selection}

All training, demographic, and habitat data evaluated in this report were collected at RCW clusters where demographic monitoring of RCW populations was conducted by Fort Stewart biologists (Figure 1). Sample clusters for this report are located in each of the six training areas (A, B, C, D, E, and F). Maneuver training is conducted in all training areas on Fort Stewart. Sample clusters in 
these areas represent an approximately 25 percent random sample of all RCW clusters occurring in these areas (Fort Stewart Endangered Species Management Plan, in draft). No sample clusters in this report were located in designated firing ranges or impact areas. Vehicle maneuver and dismounted personnel typically do not train in these areas except in designated areas (e.g., on firing lines).

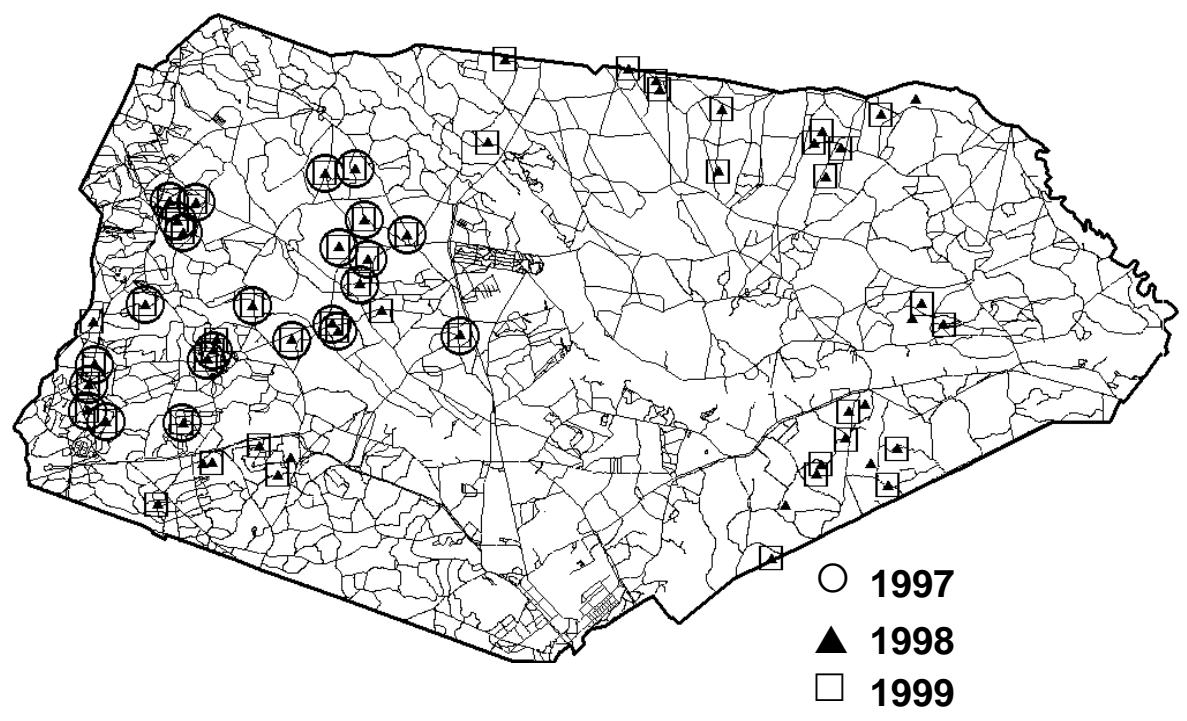

Figure 1. Location of sample clusters.

\section{Training Data Collection}

Characterizing training activity at cluster sites was done using essentially a point sample of training activity in association with monitored RCW primary clusters. The protocol described here requires minimal interaction with training units. The advantages of this approach are that it (1) characterizes training activity under actual conditions, (2) provides data that are easily statistically summarized and analyzed, and (3) requires minimal interaction with unit training so that the training "behavior" is not influenced by researcher observation.

\section{Sample Unit}

The unit of sampling at each sample cluster was a 10-minute sample observation. This time period was selected as the median of the expected maximum duration of training activities (20 minutes) in clusters based on information provided in the biological assessment of the 1994 Army guidelines (Hayden 1997). 


\section{Sample Size}

Training data from the 10-min sample observations were analyzed for 24 sample clusters from 1997. Data were analyzed for 51 dusters from 1998, and 60 dusters from 1999. A minimum of twenty 10-minute observations for each cluster were required for a cluster to be included in training activity analyses in this report. These clusters were primary clusters. Although data were also conducted at recruitment clusters during 1997-1999, these were not included in comparative analyses because recruitment clusters were at variable stages of management intervention (e.g., cavity availability) and restricted status and would not be directly comparable to primary clusters.

\section{Sampling Period}

All 10-minute sample observations were collected during the period 1 April through $30 \mathrm{~J}$ une in 1997-1999. This calendar period coincides with the peak season for RCW reproductive and nesting activities.

\section{Sampling Protocol}

The following protocol was developed to balance sampling efficiency with temporal and spatial randomization and representation of sampling observations.

- Sample clusters were allocated into sample groups to increase travel efficiency between cluster sites.

- Observations in sample groups were conducted in one of three diurnal periods: Morning - sunrise to $4 \mathrm{~h}$ post-sunrise; Mid-Day - $4 \mathrm{~h}$ post-sunrise to $4 \mathrm{~h}$ before sunset; Evening - $4 \mathrm{~h}$ before sunset to sunset.

- Observations in sample groups were rotated among diurnal periods. For example, on Day 1 sample group " $A$ " was sampled during the "Morning" period and sample group " $\mathrm{B}$ " was sampled during the "Mid-Day" period. On Day 2, sample group " $A$ " would be sampled during the "Mid-Day" period and sample group " $C$ " would be sampled during the "Evening" period, etc.

- Each sampling rotation was completed prior to the start of a subsequent sampling rotation to ensure that all clusters were sampled an equal number of times.

\section{Training Data Recorded at Sample Sites}

Table 1 provides detailed descriptions and coding for training variables recorded at sample clusters and used for analyses in this report. During each 10-minute observation period, an observer parked or walked to a cluster location, but outside the 200-foot $(61-\mathrm{m})$ radius restricted area for military training (Hayden 
1997) and recorded data on all human activity in proximity to the cluster. Human "events" were recorded if an activity was in the visual perceptual range of an RCW at the cluster site, which would be inclusive of all areas within the 200foot (61-m) buffer and would potentially include observed activities beyond the 200 -foot (61-m) buffer. Although this required a somewhat subjective judgment on the part of the observer, this determination was usually unambiguous due to the nature of the activities and the proximity of these activities to clusters. Data recorded for events observed during a 10-minute observation period included type of personnel (civilian, civilian staff, or military), number and type of vehicles and personnel, duration of event, nature of event (off-road or road transit), and notes on any other characteristics of the observed event. More than one event could occur during a 10-minute observation period. An event was defined as any related set of activities by a group of personnel or vehicles. For example, a convoy of six vehicles in road transit would be recorded as one event. A visit by Fort Stewart Fish and Wildlife Branch personnel observed during the same 10minute period would be recorded as a separate event. Data recorded included type of activity observed, number of troops and/or vehicles involved, duration of the activity, and personnel type (military, civilian, or civilian staff of Fort Stewart).

Table 1. Description and coding for variables included for analyses or data collected on Fort Stewart, Georgia in 1997-1999.

\begin{tabular}{|c|c|c|}
\hline Variable name & Description & Coding \\
\hline \multicolumn{3}{|l|}{$\begin{array}{l}\text { Dependent } \\
\text { variables }\end{array}$} \\
\hline NFLGD & Number of young fledged / breeding pair & \\
\hline \multirow[t]{2}{*}{ SUCCESS } & Were young fledged at the cluster & $0=$ No \\
\hline & & $1=$ Yes \\
\hline \multirow[t]{2}{*}{ BREEDING } & Was a breeding pair present & $0=$ No \\
\hline & & $1=$ Yes \\
\hline \multirow[t]{2}{*}{ MRET } & Breeding male retention. & $\mathrm{Y}=$ breeding male same as previous year \\
\hline & & $\begin{array}{l}\mathrm{N}=\text { breeding male from previous year not } \\
\text { present }\end{array}$ \\
\hline \multirow[t]{2}{*}{ FRET } & Breeding female retention & $\mathrm{Y}=$ breeding female same as previous year \\
\hline & & $\begin{array}{l}\mathrm{N}=\text { breeding female from previous year not } \\
\text { present }\end{array}$ \\
\hline \multirow[t]{2}{*}{ MREC } & Breeding male recruitment & $\mathrm{Y}=$ Recruitment of new breeding male \\
\hline & & $\mathrm{N}=$ No recruitment of breeding male \\
\hline \multirow[t]{2}{*}{ FREC } & Breeding female recruitment & $Y=$ Recruitment of new breeding female \\
\hline & & $\mathrm{N}=$ No recruitment of breeding female \\
\hline
\end{tabular}




\begin{tabular}{|c|c|c|}
\hline Variable name & Description & Coding \\
\hline \multicolumn{3}{|l|}{$\begin{array}{l}\text { Demographic } \\
\text { variables }\end{array}$} \\
\hline GRPN & Presence of auxiliaries with breeding pairs & $\begin{array}{l}\mathrm{Y}=\text { auxiliaries are present in group with } \\
\text { breeding pairs } \\
\mathrm{N}=\text { auxiliaries not present }\end{array}$ \\
\hline \multirow[t]{2}{*}{ PRSUC } & $\begin{array}{l}\text { Whether young were fledged at the cluster } \\
\text { in the previous year }\end{array}$ & $\mathrm{Y}=>0$ young were fledged \\
\hline & & $\mathrm{N}=0$ young were fledged \\
\hline \multirow[t]{2}{*}{ ISOL } & $\begin{array}{l}\text { Two-level k-means classification of number } \\
\text { of active clusters within two kilometers of } \\
\text { sample cluster }\end{array}$ & $\begin{array}{l}\mathrm{NO}=\text { lower level of isolation from neighbor- } \\
\text { ing clusters }\end{array}$ \\
\hline & & $\begin{array}{l}\text { YES = higher level of isolation from } \\
\text { neighboring clusters }\end{array}$ \\
\hline \multirow[t]{2}{*}{ MBRYR } & Year as breeding male in a sampled cluster & $\begin{array}{l}1 \text { = first year as breeding male in cluster } \\
\text { (may not be first year as breeder) }\end{array}$ \\
\hline & & $\begin{array}{l}2=\text { second year or more as breeding male } \\
\text { incluster }\end{array}$ \\
\hline \multirow[t]{2}{*}{ FBRYR } & $\begin{array}{l}\text { Year as breeding female in a sampled clus- } \\
\text { ter }\end{array}$ & $\begin{array}{l}1 \text { = first year as breeding female in cluster } \\
\text { (may not be first year as breeder) }\end{array}$ \\
\hline & & $\begin{array}{l}2 \text { = second year or more as breeding female } \\
\text { incluster }\end{array}$ \\
\hline \multirow{2}{*}{\multicolumn{3}{|c|}{$\begin{array}{l}\text { Habitat } \\
\text { variables }\end{array}$}} \\
\hline & & \\
\hline PINEBA & \multicolumn{2}{|l|}{ Total pine basal area / ha for cluster } \\
\hline PINEL10 & \multicolumn{2}{|l|}{ Pine BA/ha for stems < 10" DBH } \\
\hline HDBA & \multicolumn{2}{|l|}{ Hardwood BA/ha for cluster } \\
\hline PINESTM & \multicolumn{2}{|l|}{ pine stems / ha by cluster } \\
\hline HDSTM & \multicolumn{2}{|l|}{ Number of hardwood stems /ha } \\
\hline 5BURN & \multicolumn{2}{|l|}{$\begin{array}{l}\text { Total burns in } 5 \text { years prior to current breed- } \\
\text { ing season }\end{array}$} \\
\hline \multirow[t]{6}{*}{ IBURN } & $\begin{array}{l}\text { Interval of most recent burn to current } \\
\text { breeding season }\end{array}$ & $1=$ within one year \\
\hline & & $2=1-2$ years \\
\hline & & $3=2-3$ years \\
\hline & & $4=3-4$ years \\
\hline & & $5=4-5$ years \\
\hline & & $6=>5$ years \\
\hline
\end{tabular}




\begin{tabular}{|c|c|}
\hline Variable name & Description \\
\hline \multicolumn{2}{|l|}{$\begin{array}{l}\text { Training } \\
\text { variables }\end{array}$} \\
\hline NTRP & $\begin{array}{l}\text { Average RFMSS troops/day scheduled for } \\
\text { TA, Apr-June } 1998 .\end{array}$ \\
\hline NDAY & $\begin{array}{l}\text { total RFMSS days scheduled for TA, Apr- } \\
\text { June } 1998 .\end{array}$ \\
\hline ROAD & $\begin{array}{l}\text { Distance in meters from nest tree or ran- } \\
\text { domly selected cavity tree to nearest main- } \\
\text { tained road. }\end{array}$ \\
\hline L10ROAD & Log transformation of ROAD variable \\
\hline ROADCL & k-means classification of L10ROAD variable \\
\hline ACT & $\begin{array}{l}\text { Proportion of } 10-\text { min sample observations in } \\
\text { which human activity (military or civilian) } \\
\text { were observed }\end{array}$ \\
\hline MILACT & $\begin{array}{l}\text { Proportion of } 10 \text {-min sample observations in } \\
\text { which military activity were observed. }\end{array}$ \\
\hline CIVACT & $\begin{array}{l}\text { Proportion of } 10 \text {-min sample observations in } \\
\text { which civilian activity were observed. }\end{array}$ \\
\hline SITELOAD & $\begin{array}{l}\text { k-means classification of arcsine trans- } \\
\text { formed MILACT variable }\end{array}$ \\
\hline \multicolumn{2}{|l|}{ Descriptor } \\
\hline & \\
\hline CLUSTER & Ft. Stewart cluster identification number \\
\hline TA & Sub - training area designation \\
\hline AREA & Major training area designation \\
\hline YRACT & $\begin{array}{l}\text { Year the cluster was activated for occupa- } \\
\text { tion }\end{array}$ \\
\hline EVTPER & $\begin{array}{l}\text { total number of events with dismounted } \\
\text { personnel }\end{array}$ \\
\hline NUNIT8 & $\begin{array}{l}\text { total RFMSS units scheduled for TA, Apr- } \\
\text { June 1998. ("UNITNAME" by "TRA_AREA }\end{array}$ \\
\hline
\end{tabular}

\section{Training Data From G3 Range Scheduling Records}

Scheduling data from the Army's Range and Facilities Management and Scheduling System (RFMSS) for training ranges in which sample clusters were located on Fort Stewart was used to correlate scheduled training activity with field observations of training activity at sample clusters. Based on recommendations of FORSCOM and installation trainers (Army and USFWS meeting, Atlanta, GA, April 2000), variables considered in this report were: number of scheduled training days by training area, average number of troops per day scheduled by training area, and number of units scheduled per training area. RFMSS data were analyzed for the period 1 April through $30 \mathrm{~J}$ une 1998. 
Table 1 provides description and coding for training data variables derived from RFMSS for analysis in this report. RFMSS data for 1997 were not directly comparable to 1998 data. RFMSS data for 1999 were not available at the time this report was written.

\section{RCW Demographic Data}

RCW demographic data for monitored sample clusters were collected by personnel of the Fort Stewart Fish and Wildlife Branch, DPW, in accordance with methods described in the Fort Stewart ESMP approved by the installation Commander in 2001. These data have been collected in monitored clusters since 1994. Demographic variables obtained from the Fort Stewart monitoring program are described and coded in Table 1.

\section{Habitat/Site Characterization Data}

Vegetation and site data were collected at sample plots during J uly in 1998 and during J uly, August, and September in 2000. Variable description and coding for habitat data are shown in Table 1. Vegetation data collected at each sample plot included:

- Stand data: Data were collected using the point-centered quarter method (Cottam and Curtis, 1956), at five sample points within each cluster. Sample points were centered at cavity or start trees in most cases. In those cases where non-cavity or non-start trees were used, only pines that fit the parameters for installation of inserts or Copeyon starts were chosen. Basal area of pines and hardwoods was recorded using a 10X wedge prism. In each quadrant around the tree, the species, distance (to nearest $0.1 \mathrm{~m}$ ), and dbh (to nearest 0.1 inch) of the nearest canopy pine (over $15 \mathrm{~m}$ in height), the nearest midstory pine ( $2 \mathrm{~m}$ to $15 \mathrm{~m}$ in height), and the nearest hardwood (at least $2 \mathrm{~m}$ in height) all within at least 50 meters of the central tree were recorded.

- Ground and canopy cover: Data were collected al ong 100-m transects positioned such that the 50-m point intersected an imaginary perpendicular line 5-m from each tree sampled above. Canopy coverage and ground cover were recorded every $5 \mathrm{~m}$ along the transect beginning at the 5-m mark. Canopy cover included longleaf pine, loblolly pine, slash pine, pond pine, hardwood, and no canopy detected. Ground cover was recorded as bare ground, litter, graminoid (except wiregrass), wiregrass, forb, duff, dead wood, woody debris, or road. 
- Burn history: Burn history was obtained for all sample clusters based on Fort Stewart records and maps.

- Cavity number: Number of natural and artificial cavities for all sample clusters was obtained from Fort Stewart records.

\section{Statistical Analyses}

A variety of software packages were used to perform statistical analyses and tests reported in this document including SYSTAT, SPSS, and SAS. Details of the analyses are provided in the chapters reporting results (Chapters 4 through 7). A p-value less than or equal to 0.05 is considered significant for all test statistics. 


\section{Summary of Observed Activity}

As described in Chapter 2,10-minute sample observations were conducted at RCW sample clusters during 1 April - 30 J une, 1997-1999 to evaluate human activity in proximity to RCW clusters. The number of monitored clusters with more than twenty 10-minute sample observations was 24, 51, and 60 in 1997, 1998 and 1999, respectively. The increase to 51 in 1998 was due to including monitored clusters on the east side of Fort Stewart, for which no 10-minute observation samples were obtained in 1997. The increase to 60 clusters in 1999 was through the addition of clusters that were first activated by artificial nest cavities in 1998 and 1999. The average number of 10-minute observations per cluster was 26.1, 37.8, and 32.6 in 1997, 1998 and 1999, respectively

The relative frequency of vehicle types observed in 1997-1999 are show in Figure 2. Total numbers and breakdown by vehide type are shown in Table 2. Note that civilian and civilian staff vehicles were typically $4 X 4$ trucks, with the exception of a limited number of earth-movers performing road maintenance. "Light wheeled military" vehicles include Humvees and $4 X 4$ light utility trucks. "Heavy wheeled military" includes all wheeled vehicles with three or more axles. "Tracked military" includes all tracked vehicle types observed including M1 tanks, Bradley AFVs, M113 APCs, and MLRS. Tracked military vehicles comprised no more that 10.7 percent (1997) of the total number of observed vehicles in any year. The percentage of civilian and civilian staff vehicles combined ranged from 22.7 percent in 1997 to 30.0 percent in 1998.

The proportion of human activity observed in proximity to clusters during the 10-minute observation periods was relatively low during the years 1997-1999. The mean percentage of observations in which human activity was observed in proximity to clusters never exceeded 8.5 percent of the total observation periods (Table 3). Observations of military activity when averaged across clusters by year ranged from 3.2 percent in 1998 to 6.0 percent in 1997 (Table 3, Figure 3). The proportion of observations of civilian activity in proximity to clusters was similar to observations of military activity (Table 3). Observations of civilian activity ranged from an average of 2.8 percent in 1997 to 5.5 percent in 1998. 


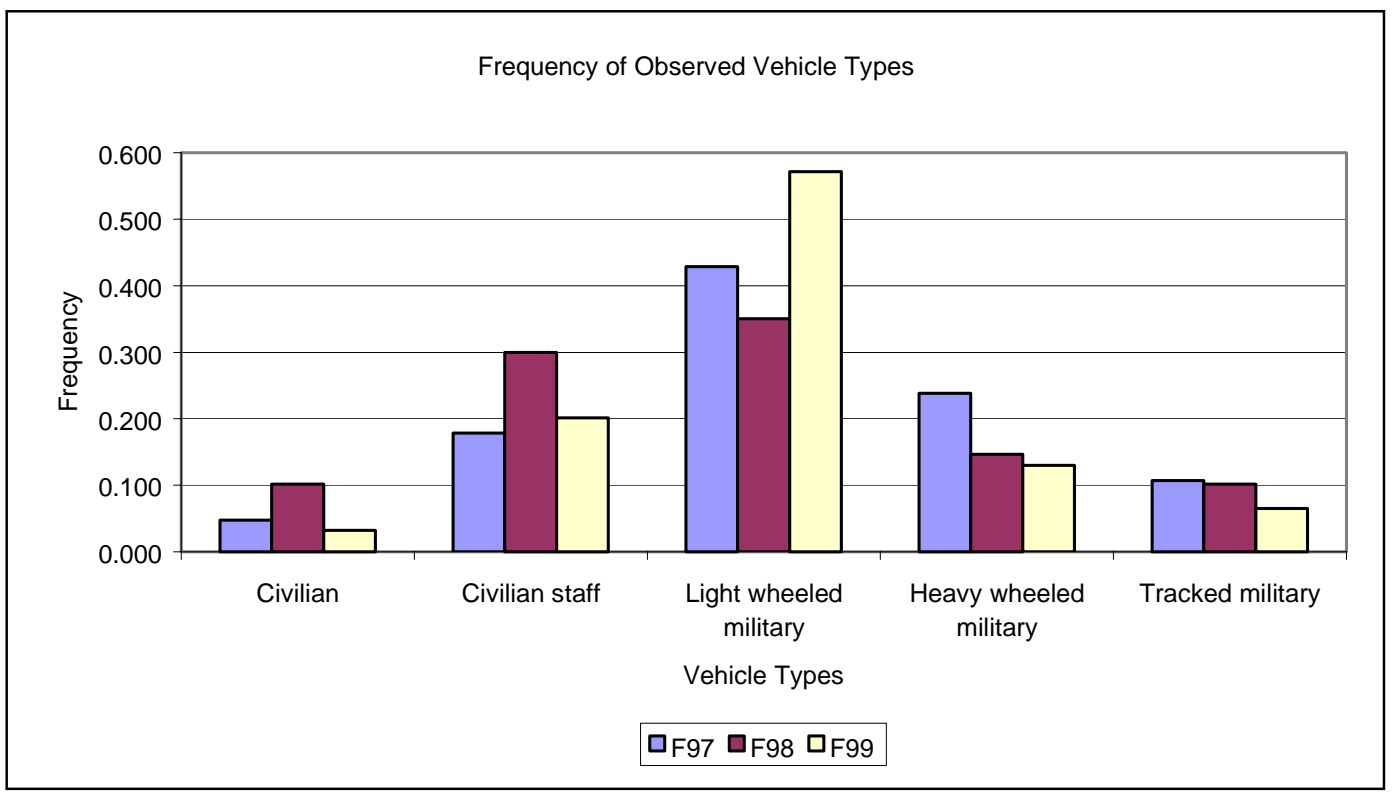

Figure 2. Relative frequency of vehicle type observed during 10-minute sample observations during 1997-1999*.

Table 2. Observed vehicle types during 10-minute sample observations, 1997-1999.

\begin{tabular}{|c|c|c|c|c|c|c|}
\hline Vehicle Type ${ }^{\star}$ & \begin{tabular}{|l} 
Number \\
1997
\end{tabular} & $\%$ & $\begin{array}{l}\text { Number } \\
1998\end{array}$ & $\%$ & $\begin{array}{l}\text { Number } \\
1999\end{array}$ & $\%$ \\
\hline Civilian & 4 & 4.8 & 18 & 10.2 & 10 & 3.2 \\
\hline Civilian staff & 15 & 17.9 & 53 & 29.9 & 62 & 20.1 \\
\hline Light wheeled military & 36 & 42.9 & 62 & 35.0 & 176 & 57.1 \\
\hline Heavy wheeled military & 20 & 23.8 & 26 & 14.7 & 40 & 13.0 \\
\hline Tracked military & 9 & 10.7 & 18 & 10.2 & 20 & 6.5 \\
\hline Total & 84 & & 177 & & 308 & \\
\hline
\end{tabular}

* "Civilian" vehicles are nonmilitary and nonstaff vehicles. "Civilian staff" are vehicles operated by Fort Stewart civilian personnel. "Light wheeled military" are all two-axled wheeled including Humvees and light-duty trucks. "Heavy wheeled military" are all military wheeled vehicles with three or more axles. "Tracked military" are all military tracked vehicles including M1 series tanks, Bradley AFVs, M113 APCs, and MRLS. Percent column is percent of total number of vehicles for each vehicle type.

Table 3. Average percentage of 10-minute observation periods with observed events per monitored cluster.

\begin{tabular}{|llllllllll|}
\hline & \multicolumn{10}{c|}{ Mean percentage of observations with observed activity } & & \\
Activity Type & $\% \mathbf{1 9 9 7}$ & $\mathbf{N}^{*}$ & SD & \% 1998 & $\mathbf{N}$ & SD & $\% \mathbf{1 9 9 9}$ & $\mathbf{N}$ & SD \\
All activity & 8.5 & 24 & 13.0 & 6.1 & 51 & 7.9 & 6.2 & 60 & 10.8 \\
Military activity & 6.0 & 24 & 10.4 & 3.2 & 51 & 5.5 & 3.7 & 60 & 8.7 \\
\hline Civilian Activity & 2.8 & 24 & 4.8 & 5.5 & 51 & 4.2 & 3.0 & 60 & 4.1 \\
\hline
\end{tabular}

* $\mathrm{N}=$ number of clusters monitored. $\mathrm{SD}=$ standard deviation of the mean. 
Mean frequency of military observations by year

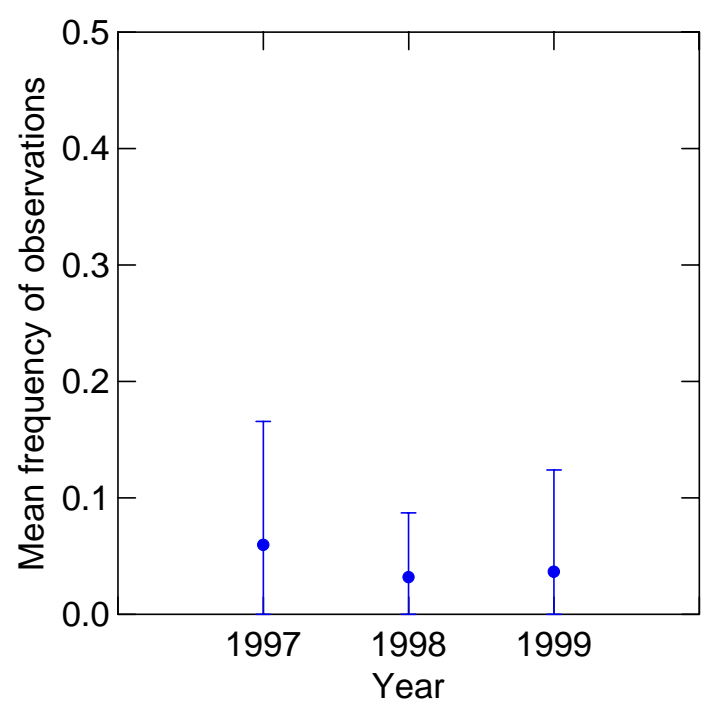

Figure 3. Mean proportion of 10-minute sample observations in which military activity was observed during 1997-1999.

The bar charts in Figures 4 through 6 show the proportion of 10-minute observations with observed activity by cluster for total activity, military activity, and civilian activity, respectively. The clusters in these figures are rank-ordered by their 3-year average of the proportion of observations with activity. Note that the level of activity in relation to individual clusters is relatively consistent across years; i.e., clusters with low frequencies of observed activity tend to be low for all years and clusters with high frequencies tend to have high levels of activity in all 3 years. The range of frequencies of 10-minute observation periods with observed total activity in proximity to clusters was $0.00-0.53$. The range of observed frequencies for military and civilian activity was $0.00-0.46$ and $0.00-$ 0.19 , respectively. 


\section{Frequency of observations with civilian and/or military} activity

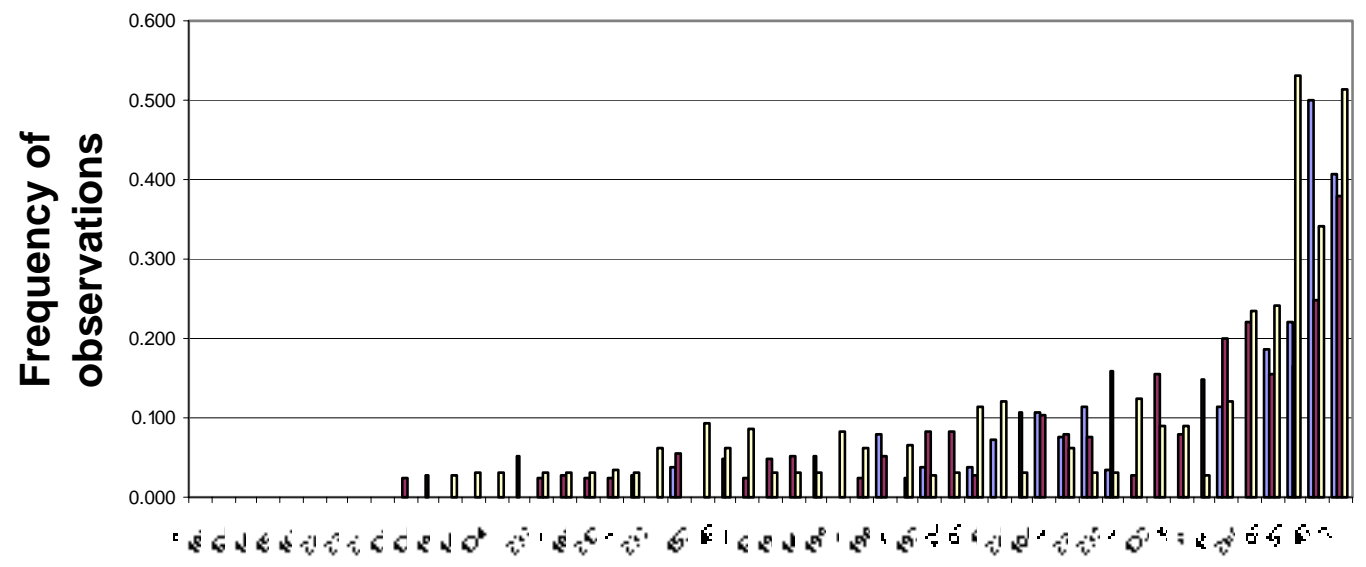

Cluster identification number

口TOTACT7 口TOTACT8 口TOTACT9

Clusters are ordered on the $\mathrm{x}$-axis by average proportion of observations of activity over the 3-year period.

Figure 4. Proportion of observed total human activity during 10-minute sample observations during 1997-1999.

\section{Frequency of observations with military activity}

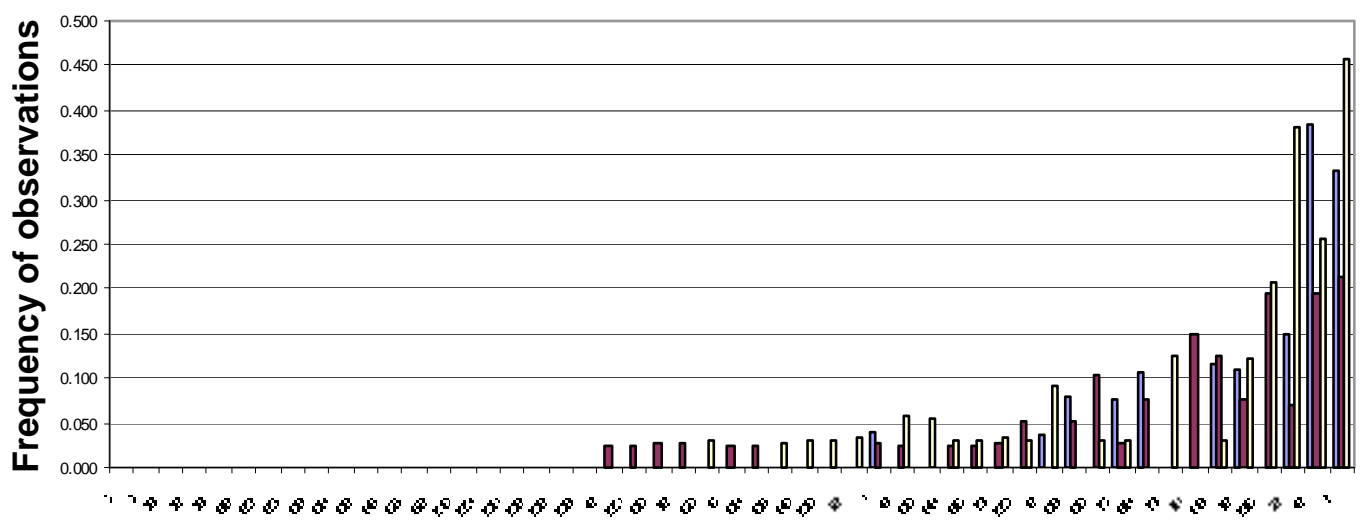

Cluster identification number

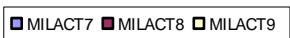

Clusters are ordered on the $\mathrm{x}$-axis by average proportion of military observations of activity over the 3year period.

Figure 5. Proportion of observed military activity during 10-minute sample observations during 1997-1999. 
Frequency of observations with civilian activity

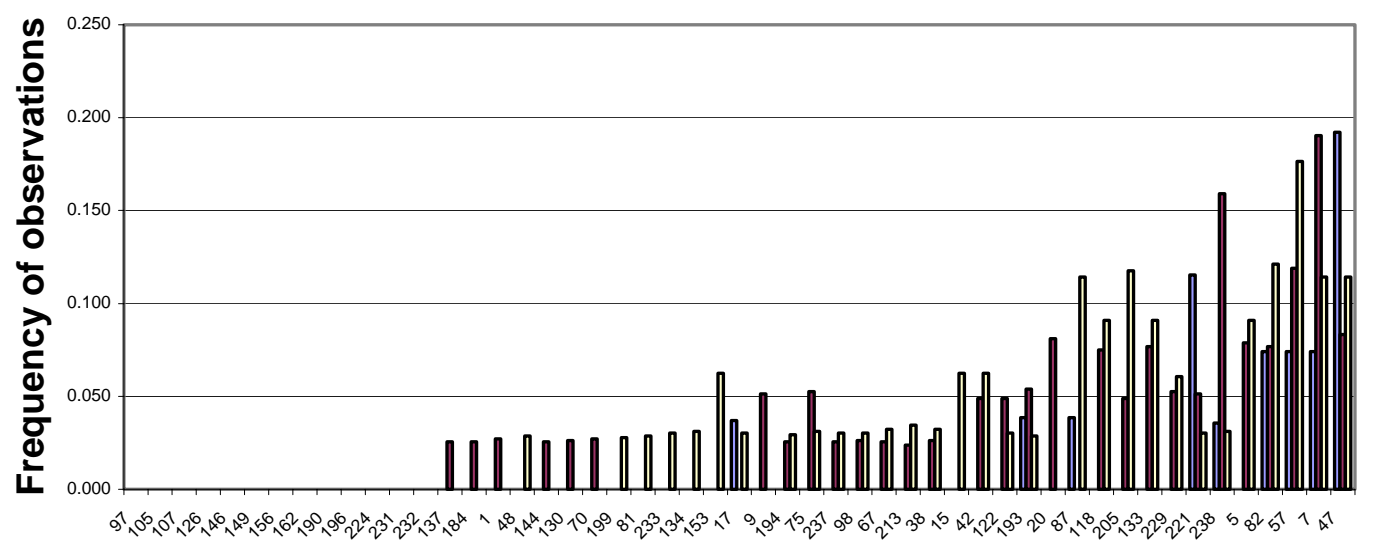

Cluster identification number

DCIVACT7 DCIVACT8 DCIVACT9

Clusters are ordered on the $\mathrm{x}$-axis by average proportion of civilian observations of activity over the 3year period.

Figure 6. Proportion of observed total human activity during 10-minute sample observations during 1997-99.

The type of activity was characterized as "off-road" and "road transit" for both civilian and military events (Table 4). Virtually all military events in proximity to RCW clusters were road transit by vehicles. No events with off-road military activity were observed in proximity to clusters in 1997 and 1999. Only 3 of 146 observed events in 1998 were military off-road activity. These events were vehicles and/or personnel parked off-road outside the 200 foot RCW cluster buffer zone. Table 4 also shows the percentage of events that involved dismounted personnel (individuals on foot) versus strictly vehicular traffic. Overall, dismounted activity was relatively low for all years ranging from 13.5 percent in 1997 to 14.4 percent in 1998.

RCW management and monitoring checks by Fort Stewart DPW and Fish and Wildlife Branch personnel comprised virtually all of the off-road events observed during the 3 years of this study. In 1998, 23 of 146 observed events (15.8 percent) were civilian off-road activities within, or in proximity to, RCW clusters. In 1997 and 1999 civilian off-road events comprised 13.5 percent and 15.5 percent, respectively, of the total observed events. These personnel were primarily performing duties associated with RCW monitoring, management, and research activities, which was consistent with training regulations in effect during the period of this study. 
Table 4. Events of human activity observed in proximity to RCW clusters.

\begin{tabular}{|l|l|l|l|l|l|}
\hline Year & $\begin{array}{l}\text { Total } \\
\text { Events } \\
\text { Observed* }\end{array}$ & Off-road & Road-transit & $\begin{array}{l}\text { Dismounted } \\
\text { Personnel }\end{array}$ & Vehicle Traffic \\
\hline 1997 & 74 & $10(13.5)$ & $64(86.5)$ & $10(13.5)$ & $64(86.5)$ \\
\hline 1998 & 146 & $26(17.8)$ & $120(82.2)$ & $21(14.4)$ & $125(85.6)$ \\
\hline 1999 & 168 & $26(15.5)$ & $142(84.5)$ & $24(14.3)$ & $144(85.7)$ \\
\hline
\end{tabular}

* Total events observed" are all activity events observed by year. More than one event may be recorded in each 10-minute observation period. Events are classified as "off-road" or "road-transit" and "dismounted personnel" or "vehicle traffic." "Off-road" events are observations of vehicles or personnel off of maintained roads or trails in proximity to RCW clusters. Road transit events are observations of vehicles or personnel traveling on maintained roads or trails. Dismounted personnel are events in which dismounted personnel were observed in proximity to RCW clusters. Percentage of total events is in parentheses. Vehicle traffic is any vehicle activity without associated dismounted activity. 


\section{Relationship of Range Scheduling Data and Observations}

\section{Analyses}

RFMSS data were obtained for Fort Stewart for 1998 to evaluate the relationship between scheduled training events and observations of site-specific training activity during 10-minute sample observations at sample cluster sites. RFMSS data from 1 April - $30 \mathrm{~J}$ une were selected coincident with the period of collection of 10-minute sample observations.

Two variables were derived from RFMSS database for this analysis. The first was the total number of days scheduled by training area (NDAY) during April$J$ une. The second was the average number of troops scheduled per day by training area (NTRP) during April-J une. These variables were identified by Army trainers as the most consistently available variables across RF MSS versions, the most likely to be consistently entered in the database, and the easiest to interpret relative to scheduled training loads.

In addition, proximity to roads was considered a potential factor in the likelihood of observing training activities in proximity to RCW clusters. Data were collected for each sample cluster for straight-line distance to the nearest maintained road (ROAD, Table 1).

The dependent variable used in these analyses is the proportion of 10-minute sample observations with observed military activity during April-J une 1998.

The Spearman rank correlation matrix for these variables is shown in Table 5. Strong correlations were identified between average number of troops scheduled per day (NTRP) and total training days (NDAY) scheduled (Spearman rank coefficient $=0.983$ ). No other strong correlations among pairs of variables were identified.

The variables NDAY and ROAD were retained for multivariate analyses of predictive models for site-specific training levels. Of the correlated variables NDAY 8 (NDAY in 1998) and NTRP8, the latter was excluded because the values 
entered into RFMSS represent the troop numbers of the unit scheduled for training but not necessarily the number of troops actually training, while NDAY more closely represents the number of days troops were training in the scheduled training areas.

Table 5. Spearman rank correlation matrix for military training variables and cluster proximity to roads.

\begin{tabular}{|l|l|l|l|l|}
\hline & MILACT $^{\star}$ & ROAD & NDAY & NTRP \\
\hline MILACT & 1.000 & & & \\
\hline ROAD & 0.135 & 1.000 & & \\
\hline NDAY & 0.257 & 0.148 & 1.000 & \\
\hline NTRP & 0.260 & 0.151 & 0.983 & 1.000 \\
\hline
\end{tabular}

* All scheduling data and cluster site data are for year 1998. Variables in this matrix are not transformed. MILACT = proportion of 10-minute observations in which training activities were observed. $R O A D=$ proximity of cluster (nest cavity tree or nearest active cavity tree) to nearest maintained road. $N D A Y=$ number days with scheduled training events during April - June 1998. NTRP $=$ average number of troops scheduled per day.

Multivariate regressions were performed to evaluate the prediction of sitespecific levels of training from data on range scheduling and cluster proximity to road. The dependent variable in these regressions was the proportion of 10minute sample observations in which military activity was observed (MILACT). The independent (predictor) variables in these regressions were NDAY and ROAD. Regressions were performed using the general linear model (GLM) procedure (Systat, v9.01). The values for MILACT were arcsine transformed and ROAD was log transformed to improve normality of the variable distributions. The following regression model was evaluated:

MILACT = constant + NDAY (arcsine transformed) + ROAD (log transformed)

The F-ratio (3.437) for this regression was significant ( $p=0.041$ ) as was the regression coefficient for NDAY ( $t=2.374, p=0.022$ ). However, the multiple R2 (0.125) suggests this model is a poor predictor for the dependent variable MILACT8. Inclusion of the interaction term NDAY*ROAD only slightly strengthens this relationship (multiple R2 $=0.197$ ). The weak correlation of the model with the dependent variable, examination of the residuals against predicted values, and the non-normal distribution of the variables, particularly MILACT (Figure 7), suggest that linear regression of these predictor variables may not be appropriate. 


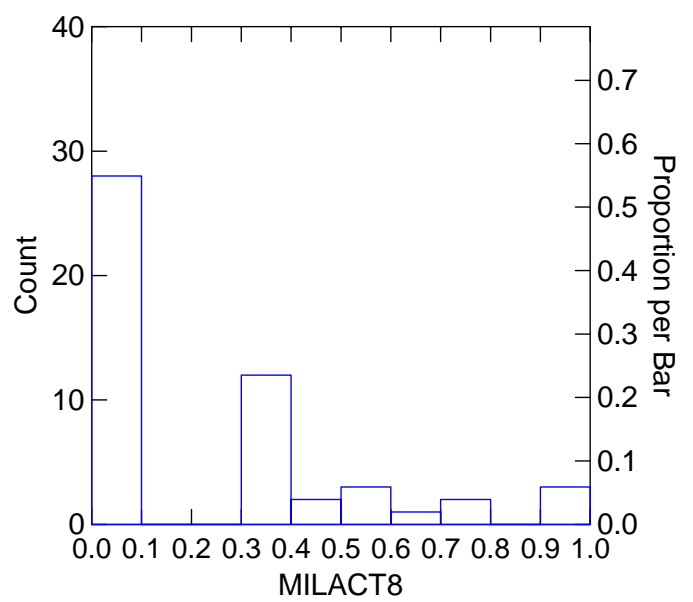

(A) proportion of military activity observed during 10-minute sample periods (MILACT, arcsine transformed)

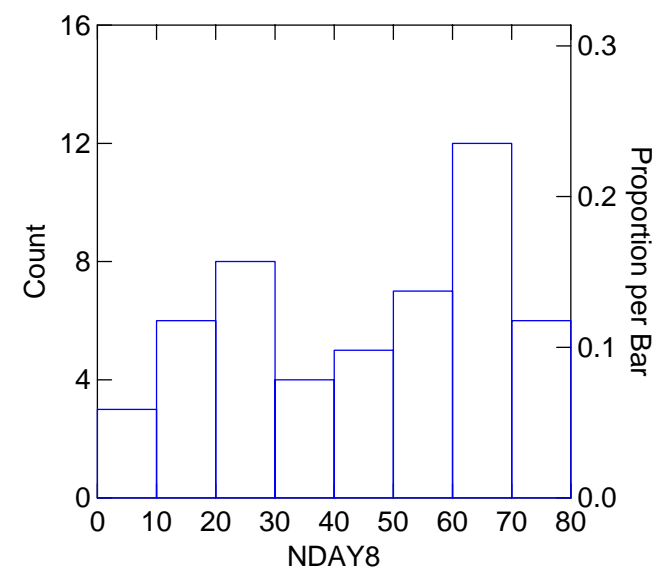

(B) Number of scheduled days of training by training area (NDAY)

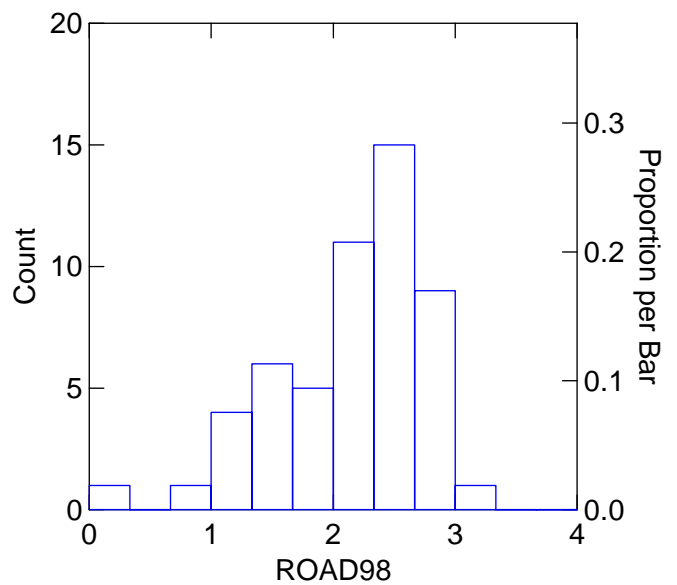

(C) Proximity of cluster to nearest maintained road (ROAD, log transformed).

Figure 7. Histograms for analysis of 1998 data. 
Because MILACT is highly skewed and weighted toward zero values, MILACT was classified as a categorical variable (SITELOAD) for values of "High" or "Low" site-specific training loads using the k-means classification procedure to split the cases into two groups. This grouping procedure classified 40 cases as "Low" site training loads (mean value of arcsine transformed variable $=0.10$ ) and 11 cases as "High" site-specific training load (mean value of arcsine transformed variable $=0.69$ ).

Logistic regression was performed with MILACT reclassified as a categorical dependent variable with two levels and the independent variables ROAD8 and NDAY8. Neither of the independent variables nor combination of variables are significant predictors ( $p>0.05$ for all variables) for the dependent variable classified as "High" or "Low" site-specific training loads. Log-likelihood ratios (indicator of model "fit") for all main effects models and models with interactions were not significant $(p>0.05)$.

\section{Discussion}

No strong correlations or predictor variables were found between range scheduling data from RFMSS and site-specific observations of training activity in proximity to cluster sites. This lack of association was not improved by including proximity to maintained roads in the regression models. This lack of association is likely due to the "resolution" of both the scheduling data used and the low proportion of observed military activity and the heavy bias toward cases with low or no observations of activity during the 10-minute observation periods. The variables analyzed from the range scheduling data provide only a coarse index of troop activity in training areas. The spatial resolution of RFMSS is at least an order of magnitude greater than the spatial resolution of duster specific observations of training activity (100's of hectares per training area versus 10's of hectares or less for cluster sites). The low proportion of observations of activity from the 10-minute sample observations is problematic for using range scheduling data or other factors such as proximity to roads as predictors of training activity at a site. The data suggest that military activity in relation to a specific cluster site is a relatively rare event with inherent statistical issues of sampling and predicting rare events. Further analysis of data available from RFMSS is required to evaluate its utility for classifying disturbance at the site level. 


\section{Data Reduction}

This chapter presents exploratory analyses and statistical models designed to reduce the "dimensions" of the extensive data set collected to evaluate effects of maneuver training on RCW populations. Over 60 measures of habitat, demographic, and training parameters initially were considered in this study. The purpose of the analyses in this chapter is to reduce the number of variables considered in final multivariate regression models for assessment of maneuver training effects on RCW populations. These analyses seek to identify redundant variables, correlations among related variables, significant associations between dependent and independent variables, adequacy of sample size, and appropriate variable transformations. Retention of variables for final analyses of training effects is based on significance of association between dependent and independent variables, adequacy of sample size, and how well they represent critical habitat, demographic, and training parameters. Related groups of independent variables (demographic, habitat, and training variables) are evaluated independently to aid interpretation of relationships among variables and measures of association with dependent variables.

Table 1 (page 14) provides descriptions and coding for all dependent variables considered in these analyses. These variables reflect critical aspects of RCW demography and provide measures of reproductive success (number of young fledged [NFLDG] and nest success [SUCCESS]) and turnover of breeding adults in cluster sites (presence of breeding pair [BREEDING], retention [MALERET, FEMRET] and recruitment [MALEREC, FEMRET] of breeding males and females). Independent (predictor) variables are those parameters known to be or potentially related to $\mathrm{RCW}$ reproductive success and/or adult retention.

\section{Demography}

This section determines the relationship of demographic parameters to number of young fledged, presence of breeding pair, nest success, breeding male and female retention, and breeding male and female recruitment. Independent variables in these analyses are GRPN, PRSUC, ISOL, MBRYR, and FBRYR (see Table 1 for definitions). MBRYR and FBRYR are class variables with two levels ( $1=$ male/female first year of breeding in cluster, $2=$ male/female second year of breeding in cluster). The range of original values for GRPN (number of 
individuals in the group) and PRSUC (how many young were fledged in the preceding year) are small (range 0 - 5 for GRPN, 0 - 3 for PRSUC), so these were transformed to class variables with two levels for these analyses. ISOL was transformed to a class variable with two levels using k-means dustering to simplify analysis with all independent variables as class variables with two levels. Treatment of all independent variables as class variables simplifies statistical treatment of the variables, simplifies comparison of results among variables, and avoids problems associated with non-normal distributions of the original variables.

Figure $8(\mathrm{~A})$ shows that the mean number of young fledged by breeding pairs without auxiliaries was lower in all years than breeding pairs with auxiliaries. Mean number of young fledged was also consistently lower in clusters where young were not fledged in the previous year versus clusters where young were fledged in the previous year [Figure 8(B)]. Clusters classified as "isolated" from other active clusters under the k-means classification procedure also fledged fewer young than clusters that were relatively less isolated [Figure (8C)]. No consistent differences in the number of young fledged are apparent relative to experience of the breeding male or female in the cluster [Figures 8(D) and 8(E)].

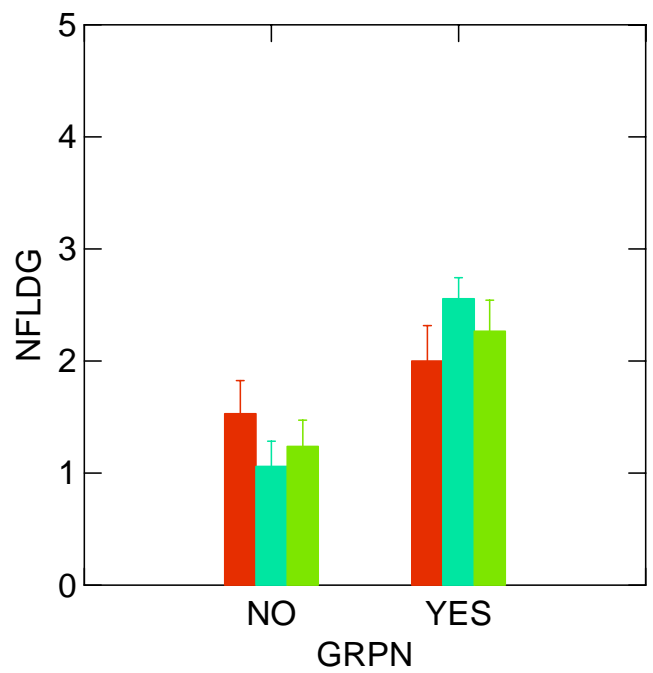

YEAR
1997
1998
1999

Figure 8 (A) GRPN: GRPN "NO" = pairs without auxillaries and "YES" = pairs with helpers. 


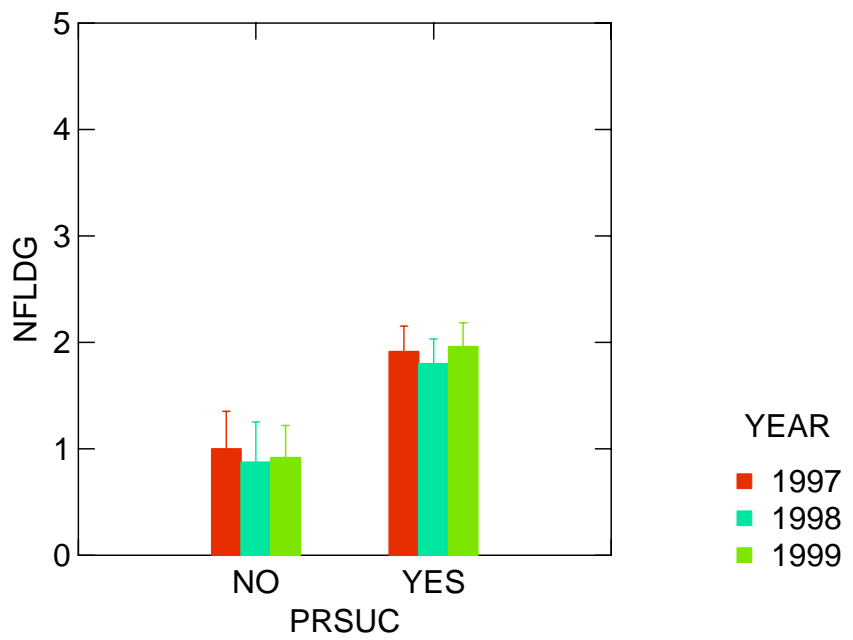

Figure 8 (B) PRSUC: PRSUC "NO" = no successful nesting attempts in the previous year and "YES" = successful nesting attempt in the previous year.

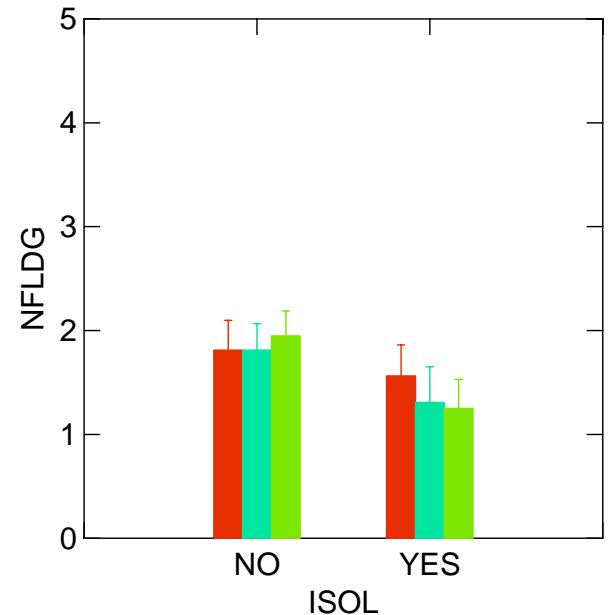

YEAR

- 1997

- 1998

- 1999

Figure 8 (C) ISOL: ISOL "NO" = k-means classification categorical indicating reduced cluster isolation and "YES" = k-means classification categorical variable indicating increased cluster isolation.

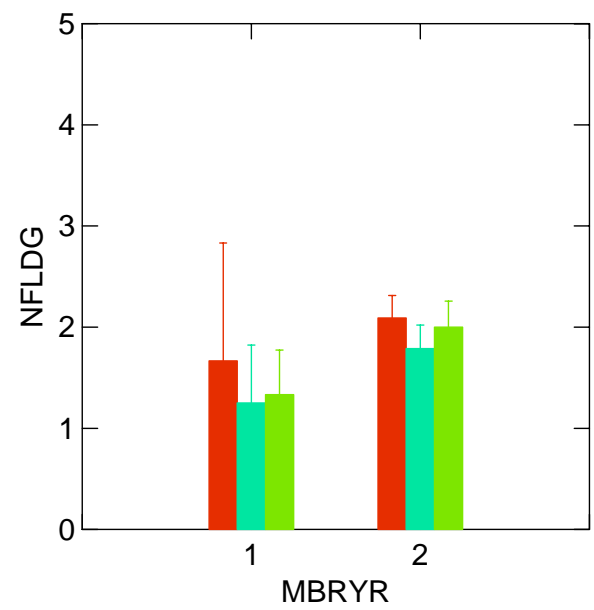

Figure 8 (D) MBRYR: See Table 1 for coding. 


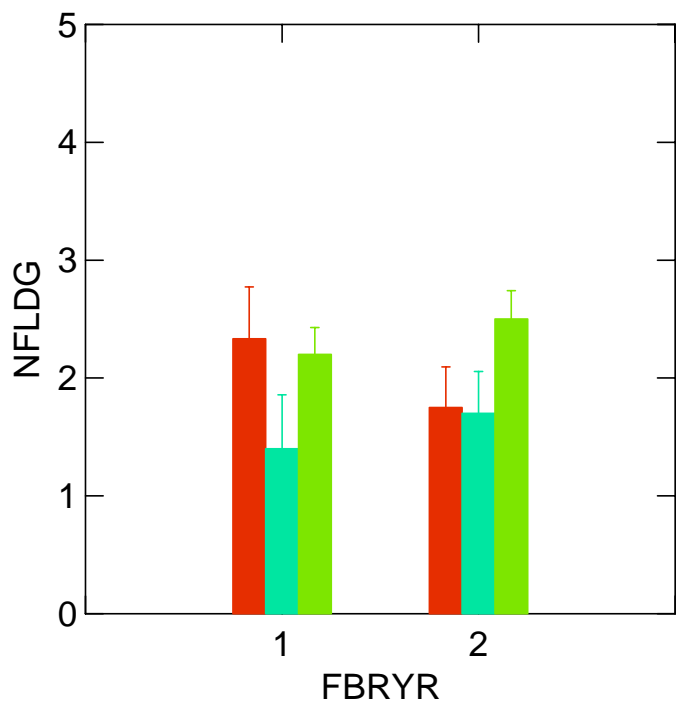

YEAR

- 1997

- 1998

1999

Figure 8 (E) FBRYR: See Table 1 for coding.

Figure 8. Mean number of fledged by year, grouped by independent variables.

Table 6 summarizes Mann-Whitney $U$ test statistics and probability values for means of number of young fledged grouped by independent class variables. The dependent variable, mean number of young fledged, was significantly different in 1998 and 1999 for breeding pairs with auxiliaries versus those without auxiliaries. Number of young fledged was significantly higher in all years in clusters where young were fledged in the previous year. Although clusters that were more isolated consistently fledged fewer young in all years, the means were only significantly different in 1999. Neither male nor female breeding tenure in the cluster had any significant effect on number of young fledged in any year; however, sample sizes for these two variables were relatively small, particularly for adults in their first breeding year.

Table 6. Non-parametric means test for NFLDG grouped by demographic variables.

\begin{tabular}{|l|l|l|l|l|l|l|l|l|l|}
\hline & \multicolumn{2}{l}{1997} & \multicolumn{2}{l}{1998} & \multicolumn{2}{l|}{1999} \\
\hline $\begin{array}{l}\text { Grouping } \\
\text { variables }\end{array}$ & M-W U* & $\mathrm{p}$ & $\mathrm{N}$ & $\mathrm{M}-\mathrm{W} \mathrm{U}$ & $\mathrm{p}$ & $\mathrm{N}$ & $\mathrm{M}-\mathrm{W} \mathrm{U}$ & $\mathrm{p}$ & $\mathrm{N}$ \\
\hline GRPN & 78.5 & 0.280 & 29 & 14.0 & 0.000 & 26 & 77.5 & 0.008 & 36 \\
\hline PRSUC & 48.5 & 0.041 & 31 & 42.00 & 0.041 & 28 & 74.5 & 0.011 & 37 \\
\hline ISOL & 144.0 & 0.530 & 32 & 130.5 & 0.222 & 29 & 258.5 & 0.045 & 39 \\
\hline MBRYR & 14.5 & 0.736 & 14 & 25.5 & 0.271 & 23 & 17.0 & 0.215 & 23 \\
\hline FBRYR & 23.0 & 0.452 & 15 & 20.0 & 0.504 & 15 & 22.5 & 0.380 & 17 \\
\hline
\end{tabular}

* $\mathrm{M}-\mathrm{W} U=$ Mann-Whitney $\mathrm{U}$ test statistic. $\mathrm{p}=$ significance value for test statistic. $\mathrm{N}=$ total sample size. 
The other dependent variables considered in these analyses were class variables with two levels. Since the independent variables were also class variables with two levels, $2 \times 2$ tables were analyzed to test the association between the dependent and independent variables. Table 7 shows Fisher's exact test probabilities for these tests of independence. Significance values are not shown for some $2 \times 2$ tables because of the relationship between the independent and dependent variables. This is the case for MBRYR and FBRYR by MALEREC and FEMREC, respectively. In this case, the dependent and independent variables are providing essentially the same information (breeding tenure in the cluster) so measure of association is trivial. A similar relationship occurs with MALEREC and FEMREC with PRSUC. FEMREC and MALEREC implies in most cases that a breeding male was not present in the previous year, which also implies no young fledged in the previous year. The variable PRSUC essentially provides the same information. There is also a trivial comparison for GRPN and BREEDING, where the class variable GRPN assumes presence of a breeding pair. In several instances there were no observations for one level of the dependent or independent variable so the $2 \times 2$ table could not be constructed. This was primarily the case for those variables that were dependent on identification of banded birds (dependent variables MALERET, MALEREC, FEMRET, and FEMREC, and independent variables MBRYR and FBYR).

Table 7 shows that the only consistently significant association is between whether a breeding pair is present and whether young were fledged in the previous year at the cluster. No other tests of independence were consistently rejected for any of the other pairs of independent and dependent variables. Note, however, that sample sizes were relatively small for the dependent variables MALERET, MALEREC, FEMRET, and FEMREC, and the independent variables MBRYR and FBRYR.

The independent variables GRPN, PRSUC and ISOL will be retained for evaluation in the final predictive regression models for NFLDG, SUCCESS, and BREEDING. However, the dependent variables MALERET, MALEREC, FEMRET, and FEMREC, and the independent variables MBRYR and FBRYR will not be evaluated in the final model. These variables are dependent on observations of banded birds and exhibit a high frequency of missing values in the data. Further analyses of these variables would be uninformative due to low sample sizes resulting from missing data. 
Table 7. Significance values for Fisher's exact test of independence between dependent variables (rows) and independent variables (columns) 1997-1999.

\begin{tabular}{|c|c|c|c|c|c|}
\hline \multirow[b]{2}{*}{$\begin{array}{l}\text { Dependent } \\
\text { variables }\end{array}$} & \multicolumn{5}{|c|}{ Independent variables } \\
\hline & GRPN & PRSUC & ISOL & MBRYR & FBRYR \\
\hline $\begin{array}{l}\text { BREEDING } \\
1997 \\
1998 \\
1999\end{array}$ & see $^{1}$ & $\begin{array}{l}0.000 \\
0.000 \\
0.000\end{array}$ & $\begin{array}{l}0.552 \\
0.039 \\
0.192\end{array}$ & $\begin{array}{l}0.250 \\
1.000 \\
*\end{array}$ & $\begin{array}{l}1.000 \\
* \\
*\end{array}$ \\
\hline $\begin{array}{l}\text { SUCCESS } \\
1997 \\
1998 \\
1999\end{array}$ & $\begin{array}{l}0.354 \\
0.063 \\
0.104 \\
\end{array}$ & $\begin{array}{l}0.335 \\
0.142 \\
0.036 \\
\end{array}$ & $\begin{array}{l}1.000 \\
0.667 \\
0.273 \\
\end{array}$ & $\begin{array}{l}0.214 \\
1.000 \\
1.000 \\
\end{array}$ & $\begin{array}{l}1.000 \\
1.000 \\
*\end{array}$ \\
\hline $\begin{array}{l}\text { MALERET } \\
1997 \\
1998 \\
1999\end{array}$ & $\begin{array}{l}0.258 \\
1.000 \\
0.093\end{array}$ & $\begin{array}{l}1.000 \\
0.217 \\
0.470\end{array}$ & $\begin{array}{l}0.229 \\
1.000 \\
0.560\end{array}$ & see $^{2}$ & $\begin{array}{l}0.378 \\
0.273 \\
0.505\end{array}$ \\
\hline $\begin{array}{l}\text { MALEREC } \\
1997 \\
1998 \\
1999\end{array}$ & $\begin{array}{l}* \\
* \\
*\end{array}$ & $\mathrm{see}^{3}$ & $\begin{array}{l}0.077 \\
0.547 \\
1.000 \\
\end{array}$ & $\begin{array}{l}* \\
* \\
*\end{array}$ & $\begin{array}{l}* \\
* \\
* \\
\end{array}$ \\
\hline $\begin{array}{l}\text { FEMRET } \\
1997 \\
1998 \\
1999 \\
\end{array}$ & $\begin{array}{l}0.486 \\
0.228 \\
0.620 \\
\end{array}$ & $\begin{array}{l}0.008 \\
1.000 \\
0.450 \\
\end{array}$ & $\begin{array}{l}0.467 \\
1.000 \\
1.000 \\
\end{array}$ & $\begin{array}{l}0.378 \\
0.091 \\
0.505 \\
\end{array}$ & $\operatorname{see}^{2}$ \\
\hline $\begin{array}{l}\text { FEMREC } \\
1997 \\
1998 \\
1999\end{array}$ & $\begin{array}{l}* \\
* \\
*\end{array}$ & see $^{3}$ & $\begin{array}{l}0.176 \\
0.277 \\
0.266\end{array}$ & $\begin{array}{l}* \\
* \\
*\end{array}$ & $\begin{array}{l}* \\
* \\
*\end{array}$ \\
\hline
\end{tabular}

* No values observed for one level of dependent variable.

1 GRPN variable implies presence of breeding pair. Test of association with BREEDING (presence or absence of breeding pair) is trivial.

${ }^{2}$ Dependent and independent variables are essentially providing the same information; e.g., a male in its second year of breeding in a cluster (MBRYR) will be a returning breeder from the previous year (MALERET). Tests of association for these variables are trivial.

3 MALEREC and FEMREC implies in most cases that a breeding male was not present in the previous year, which also implies no young fledged in the previous year. The variable PRSUC essentially provides the same information making these tests of independence trivial.

\section{Habitat}

Before analysis, several calculations were performed on collected habitat data. Basal area of pines and hardwoods within clusters, estimated via assessments with a ten-factor prism, was converted into metric units ( $\mathrm{m}^{2}$ per hectare). Pine basal area estimates were then subdivided into two size classes in each cluster: 
trees greater than $25.4 \mathrm{~cm}$ in diameter (overstory) and trees less than $25.4 \mathrm{~cm}$ in diameter (understory). Number of stems per hectare for pines and hardwoods was calculated using data from point-to-plant measurements taken from nest tree centered point-quarter samples in each duster. Stems per hectare were determined for each point-quarter plot, and the average of these measurements was calculated for the entire cluster. As before, pines were grouped into greater than and less than $25.4-\mathrm{cm}$ size classes. Also, because variation in number of stems per hectare across clusters was high, estimates were log transformed before further analysis.

Percent ground cover and percent canopy cover for each cluster were determined via ocular estimates along transects in each of the five point-quarter plots. On each plot, these estimates were calculated from 20 sightings along five transects in each cluster. Percentages were calculated by dividing the total number of positive encounters for each category by the total observations. Both canopy cover and ground cover were subdivided into several categories (canopy - overstory and understory; ground - woody bushes, grass and forbs, open, and road). The mean of the estimates from each of the five point-quarter plots was used as an index of the cover for that layer for the entire cluster.

Because many of these habitat variables were to varying degrees correlated, we reduced the total number of variables included in the original analysis by removing those variables that showed no obvious relationship with RCW fitness variables. Cover data were not collected for all sample clusters. Analyses of available cover data indicated no relationships between cover variables and RCW success variables. Therefore, all measures of cover were eliminated from further analysis to maintain total sample size for other variables used in the analysis.

Of the variables remaining after removal of cover data, several were strongly collinear with other habitat variables. Because inclusion of many variables in a linear regression model, regardless of the strength of the relationship between predictive and predicted variables, artificially elevates the predictive power of the model, it was necessary to remove additional variables. Thus, we eliminated from further analysis those habitat variables exhibiting strong relationships ( $r^{2}$ $>0.70$ ) with other habitat variables, yet relatively weaker relationships with RCW fitness variables.

Two other types of habitat-specific data, in addition to the previous mentioned variables, were included in further analysis: cluster burn history and abundance of cavities per cluster. Burn data for all 3 years (1997-1999) was included, but data on burn history are somewhat redundant. Therefore, only data from 1998, the same year in which the habitat data was collected, were used in further 
analysis. Similarly, only data from 1998 were used for number of cavities per cluster, as using all years would produce problems of collinearity. A list and description of all habitat variables used in further analysis are provided in Table 1 (page 14).

According to exploratory correlation analyses, few habitat variables exhibited obvious relationships with RCW fitness variables. We therefore used principal component analysis (PCA), a multivariate ordination technique, to identify the major dimensions of variation within the habitat variable matrix. PCA reduces dimensionality of a data matrix by combining several measured variables into a few, more informative variables, somewhat representative of a "habitat gradient," and identifies those measured variables that are most influential to separation along the calculated gradients (see Gauch 1982 for a detailed explanation of PCA). All listed variables were included in this ordination procedure except NCAV8. This variable could have potentially complicated interpretation of gradients suggested by PCA, because this variable, unlike others, is not directly related to the habitat itself, but is a combination of both natural conditions and artificial, anthropogenic effects. Though burn history may also exhibit an anthropogenic aspect, its effects on habitat should be quite great, whereas cavity abundance may vary irrespective of actual habitat gradients.

To perform PCA, we first relativized all included variables using the general relativization function in the software package, PC-ORD v3.20. This transformation maintains variation within individual variables, yet standardizes variation between variables, therefore eliminating artifacts in ordination due to nonuniform variable distributions (McCune 1992). Next, we used the variance/covariance PCA procedure to ordinate clusters and a varimax rotation to maximize separation of these clusters along generated principal components (McCune 1992).

Scores from the first three principal components for each cluster are plotted in three-dimensional space (Figure 9). Table 8 provides information on the PCA axes produced, and Table 9 provides correlation coefficients between PCA scores and raw habitat variables after varimax rotation. Axis 1, which explained 57.96 percent of the variation in the main habitat matrix, was strongly positively correlated to hardwood basal area (Kendall's tau $r=0.891$ ). As is evident in Figure 9, most clusters along this axis occurred in relatively close proximity to each other. Very few clusters had high or low hardwood basal areas values; most were intermediate. However, though it appears that little variation exists along this axis, this variable was most important to ordination of sites, and though only a few clusters occupied extremes, all sites were tightly arranged along this habitat gradient (see above). Thus, based on the evaluated data matrix, 
between-site variation was captured by this axis. Axis 2 explained 20.84 percent of the overall variation in the habitat matrix and was strongly positively correlated to understory pine basal area (Kendall's tau $r=0.910$ ). This axis, though explaining less variation than the first, better separated RCW clusters along its length. Midstory pine basal area was more evenly distributed among sites than was hardwood basal area. Axis 3 explained 12.52 percent of the variation in the main matrix and was strongly negatively correlated to burn interval 1998 and positively correlated to number of burns in the past 5 years (Kendall's tau $r=-0.766$, and 0.573 , respectively). RCW clusters were well spread evenly along this component. An additional 4 axes explained the remaining 8.7 percent variation in the main matrix; however, because the explanatory power of these components was small in comparison to the first three axes and because no clear relationship between PC scores and measured habitat variables were identified with these axes, components four through six were eliminated from further consideration.

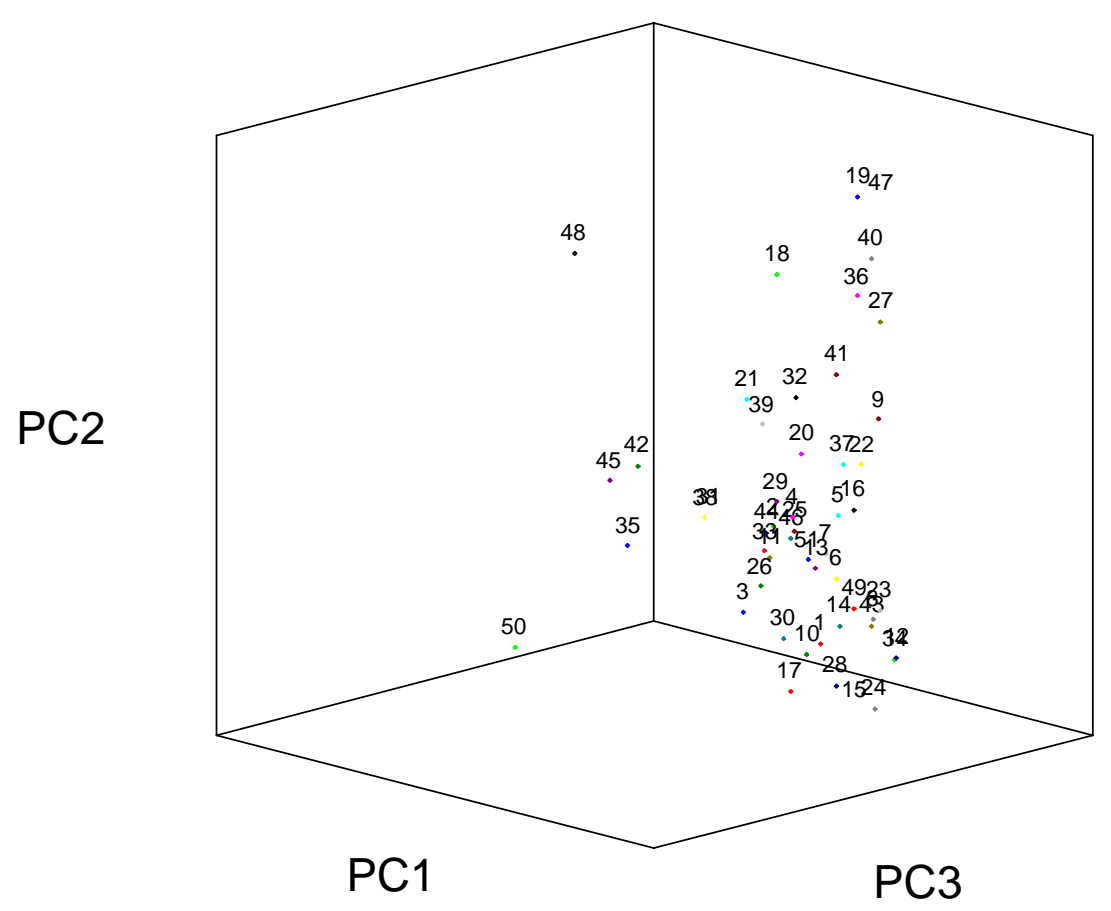

PC1 positively correlated to increasing hardwood basal area, PC2 positively correlated with increasing midstory pine basal area, and PC3 negatively correlated to 1998 burn interval.

Figure 9. Ordination of RCW clusters along first three principal components of measured habitat variables. 
Table 8. Critical values from principal component analysis of RCW cluster habitat variables.

\begin{tabular}{|l|l|l|l|}
\hline Axis & Eigenvalue & \% of Variance & Cumulative \% of Variance \\
\hline 1 & 0.033 & 57.955 & 57.955 \\
\hline 2 & 0.012 & 20.841 & 78.796 \\
\hline 3 & 0.007 & 12.516 & 91.312 \\
\hline 4 & 0.002 & 3.657 & 94.968 \\
\hline 5 & 0.002 & 2.430 & 97.398 \\
\hline 6 & 0.001 & 1.841 & 99.240 \\
\hline 7 & 0.001 & 0.760 & 100.000 \\
\hline
\end{tabular}

Table 9. Correlation coefficients of PCA scores and measured RCW cluster habitat variables after varimax rotation.

\begin{tabular}{|l|c|c|c|}
\hline & \multicolumn{3}{|c|}{ Kendall's Tau correlation coefficient with PCA axis } \\
\hline Habitat variable & $\mathbf{1}$ & $\mathbf{2}$ & $\mathbf{3}$ \\
\hline PINEBA & 0.080 & 0.280 & 0.000 \\
\hline PINEL10 & -0.163 & 0.910 & -0.161 \\
\hline HDBA & 0.891 & -0.002 & -0.207 \\
\hline PINESTML & 0.007 & 0.145 & -0.133 \\
\hline HDSTML & -0.026 & 0.296 & 0.225 \\
\hline 5BURN8 & -0.491 & 0.021 & 0.573 \\
\hline IBURN8 & 0.407 & 0.037 & -0.766 \\
\hline
\end{tabular}

To assess univariate relationships between habitat characteristics and RCW success measures, two statistical procedures were used. First, Spearman rank correlations between PC scores and number of cavities in 1998 and number of RCW fledglings per cluster (NFLDG) in all 3 years were calculated (Table 10). No significant relationships were detected in these comparisons. Furthermore, not only was significance absent, but also relationships between habitat variables and number of fledglings across years were in opposition. For example, PC2 was positively related to RCW success in 1997 but negatively associated in 1998 and 1999. This inconsistency suggests that the lack of a relationship between habitat variables and number of fledglings cannot be explained solely by low sample size. 
Table 10. Spearman rank correlation coefficients between principal components scores of measured habitat variables and number of useable RCW cavities in 1998 and number of fledglings produced by cluster for years 1997, 1998, and 1999.

\begin{tabular}{|l|l|l|l|}
\hline Habitat Variable* $^{*}$ & \# Fledglings 1997 & \# Fledglings 1998 & \# Fledglings 1999 \\
\hline PC1 & -0.349 & -0.256 & -0.104 \\
\hline PC2 & 0.046 & -0.037 & -0.058 \\
\hline PC3 & 0.127 & -0.238 & -0.225 \\
\hline \# cavities 1998 & -0.027 & 0.328 & 0.198 \\
\hline
\end{tabular}

* No relationships were statistically significant $(P<0.05)$.

Next, logistic regression was used to assess relationships between habitat variables and binomial RCW success variables including breeding pair presence (BREEDING), successful fledging (SUCCESS), male/female recruitment (MREC/FREC), and male/female retention (MRET/FRET) (Table 11). As with fledgling number, no consistent relationships were identified across all three years, though significant predictive power was indicated in two cases: breeding pair presence in 1997 by PC2 scores and in 1999 by number of cavities. Such relationships, however, are likely spurious.

In conclusion, it appears that though principal component analysis adequately captured habitat variability, this variability did not explain variation in RCW success across clusters: no significant trends between principal component scores and measures or RCW success were detected. Furthermore, the number of cavities present in the area, a variable that has been shown previously to be influential to RCW success, was not significantly predictive of RCW fitness here.

Such lack of relationships may be due to several factors. First, it is possible that in fact no relationships do exist. Most previous studies of RCW success have had difficulty identifying specific habitat variables that are predictive of RCW success. Most variables that have been identified are not large scale, physiognomic variables like the ones identified here, but instead they are nest site specific. Second, habitat conditions among clusters evaluated in this study may not have been sufficiently different to affect RCW success. Though PCA did separate clusters in multidimensional space, it is possible that little variation in quality as assessed by RCWs occurred along these axes. Lastly, variables measured and included in the analysis may not have been those used by RCWs as measures of "good" habitat. As apparent from the data, certain clusters were consistently more successful across years than others. This trend implies that certain characteristics of the area do in fact influence RCW success. Perhaps the variables measured did not identify these characteristics, thus no significant habitat-RCW success relationships were indicated. 
Table 11. Critical values (Wald statistic (W) and P-value (P)) from logistic regression analyses of principal component scores of habitat variables and number of useable RCW cavities in 1998 and binomial measures of RCW reproductive success in the years 1997-1999.

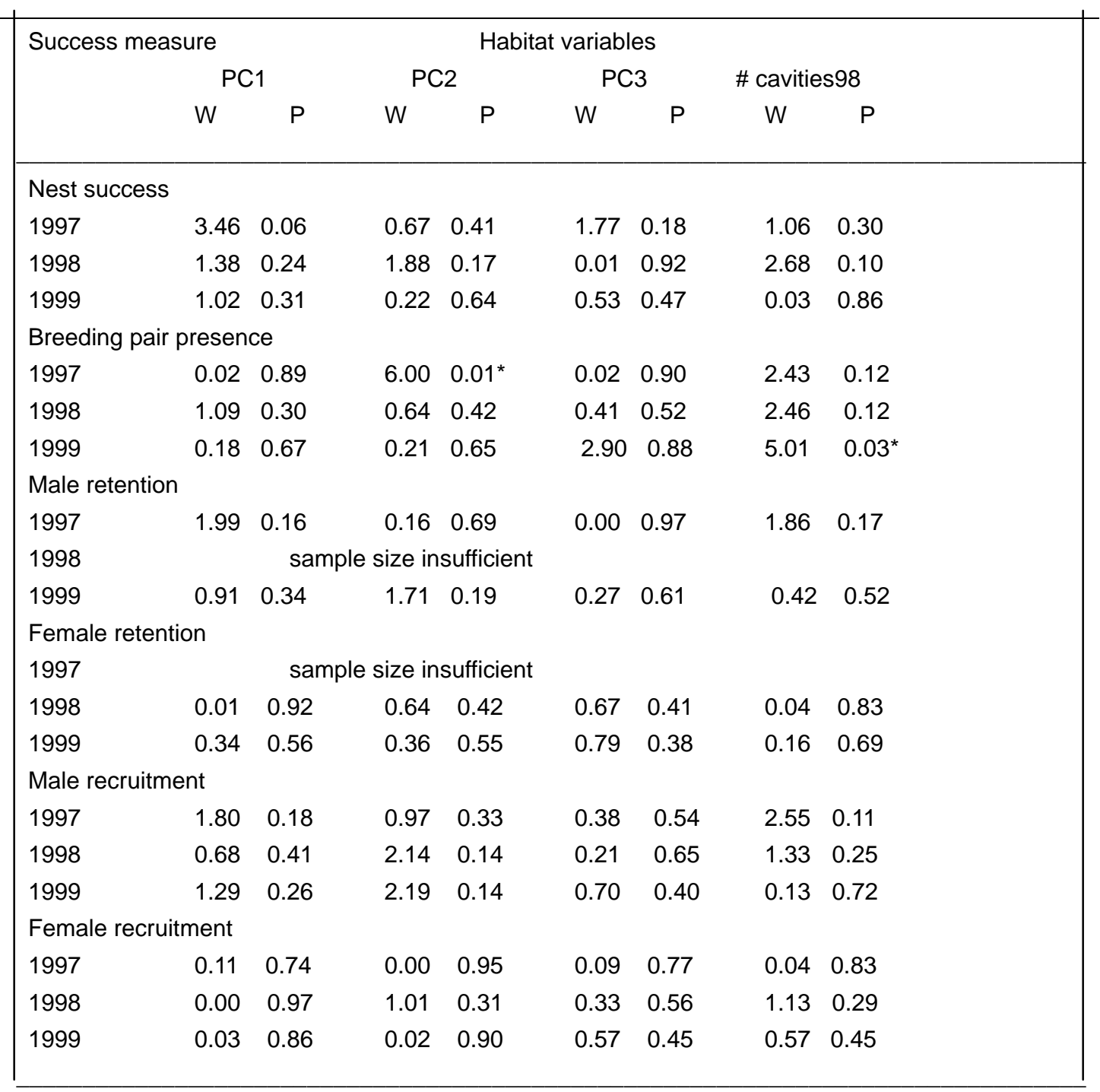

* indicates significant $P$-value $(<0.05)$

\section{Human Disturbance}

Measures of human disturbance in proximity to RCW clusters were examined for effects on RCW demographic measures. Dependent variables in these analyses were nest success in clusters with a breeding pair (SUCCESS; did a nest fledge at least one young), number of young fledged from clusters with a breeding pair (NFLDG), presence of breeding pair (BREEDING), male and female adult retention (MALERET, FEMRET; retention of the breeding adult from the preceding year) and male and female adult recruitment (MALEREC, FEMREC). 
Independent (predictor) variables used were the proportion of 10-minute observations in which military activity (presence or transit of military vehicles or personnel) was observed (MILACT, arcsine transformation), proportion of 10minute observations in which any human activity (military and civilian activity) was observed (ACT, arcsine transformed), distance to maintained roads (L 1OROAD, log transformed) and number of scheduled training days (NDAY).

Table 12 shows Spearman's rank correlation matrices for number of young fledged (NFLDG), total activity observed (ACT), military activity observed (MILACT) and distance to maintained roads for the years 1997-1999 (ROAD). No strong correlations were found between number of young fledged and any of the independent measures of potential disturbance. Total activity was highly correlated (Spearman's rank correlation coefficient $>0.750$ ) with military activity in all years. Due to the strength of this correlation, the variable and derivatives of observed military activity were used for all subsequent analyses.

Table 12. Spearman rank correlation matrix for potential disturbance variables and number of young fledged, 1997-99.

\begin{tabular}{|l|l|l|l|l|}
\hline Year & NFLDG & ACT* $^{*}$ & MILACT & ROAD \\
\hline 1997 & & & & \\
\hline NFLDG & 1.000 & & & \\
\hline ACT & -0.430 & 1.000 & & \\
\hline MILACT & -0.262 & 0.837 & 1.000 & \\
\hline ROAD & 0.162 & -0.590 & -0.832 & 1.000 \\
\hline $\mathbf{1 9 9 8}$ & & & & \\
\hline NFLDG & 1.000 & & & \\
\hline ACT & 0.125 & 1.000 & & \\
\hline MILACT & 0.150 & 0.805 & 1.000 & \\
\hline ROAD & -0.009 & -0.281 & -0.367 & 1.000 \\
\hline $\mathbf{1 9 9 9}$ & & & & \\
\hline NFLDG & 1.000 & & & \\
\hline ACT & 0.123 & 1.000 & & \\
\hline MILACT & 0.060 & 0.759 & 1.000 & \\
\hline ROAD & 0.066 & -0.288 & -0.335 & \\
\hline ACT & & & & \\
\hline
\end{tabular}

* ACT and MILACT are proportions of all activity and military activity observed during 10-minute sample periods. Data are arcsine transformed. ROAD is log transformed distance of nest cavity tree or nearest active cavity tree to a maintained road. NFLDG is number of young fledged per breeding pair.

Table 13 shows results of non-parametric Kruskal-Wallis two-sample test mean number fledged on factors SITELOAD and ROAD(CLASS). SITELOAD and ROAD(CLASS) are class variables with two levels derived by k-means classification from MILACT and ROAD. These univariate means tests showed 
no statistically significant difference $(p>0.05)$ in any year in number of young fledged from clusters with higher levels of observed activity versus those with low levels of observed military activity and no difference in number of young fledged from clusters close to roads versus those distant from roads. Figures 10 and 11 show mean number of young fledged by year for these two factors. Mean number fledged was consistently slightly lower for clusters closer to roads for all years (Figure 11) but only slightly so. No consistent trend was observed for the factor SITELOAD.

Table 13. Non-parametric means test for NFLDG grouped by SITELOAD and ROAD (CLASS).

\begin{tabular}{|l|l|l|l|l|l|l|}
\hline & \multicolumn{2}{|l|}{ SITELOAD* } & \multicolumn{2}{l|}{ ROAD (CLASS) } & $\mathrm{N}$ \\
\hline & $\begin{array}{l}\text { Mann- } \\
\text { Whitney U }\end{array}$ & $\mathrm{p}$ & $\mathrm{N}$ & $\begin{array}{l}\text { Mann- } \\
\text { Whitney U }\end{array}$ & $\mathrm{p}$ & \\
\hline NFLDG & & & & & & 32 \\
\hline 1997 & 31.0 & 0.469 & 19 & 127.0 & 0.472 & 29 \\
\hline 1998 & 98.0 & 0.473 & 29 & 78.0 & 0.610 & 39 \\
\hline 1999 & 133.5 & 0.731 & 39 & 181.0 & 0.229 & \\
\hline
\end{tabular}

* SITELOAD and ROAD (CLASS) variables have two levels based on k-means classification. $\mathrm{N}=$ sample size. $\mathrm{P}$ = significance values for Mann-Whitney $U$ test statistic.

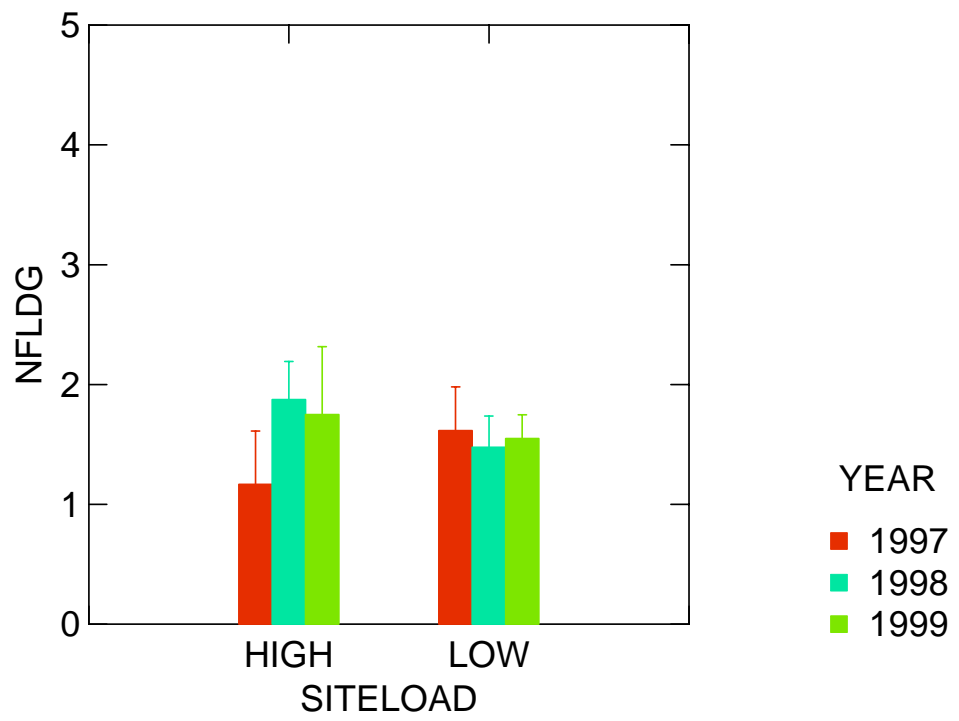

Figure 10. Mean number of young fledged by year, grouped by SITELOAD 


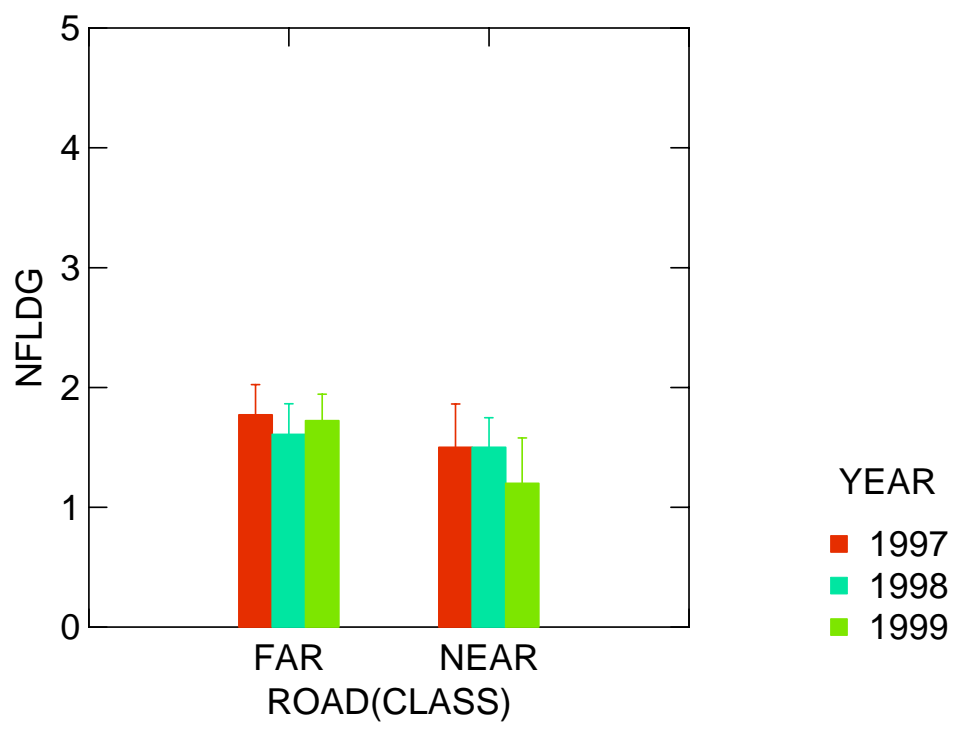

Figure 11. Mean number of young fledged by year, grouped by ROAD(CLASS).

The other dependent variables considered in these analyses are class variables with two-levels. Logistic regressions were performed with MILACT and ROAD as predictor variables for each of the independent variables SUCCESS, BREEDING, MALERET, MALEREC, FEMRET, and FEMREC. Results of these logistic regressions for all years are presented in Table 14. The independent variables were poor predictors for all the dependent variables in all years ( $p$ values for logit coefficients $>0.05$ ). Overall model fit was also generally poor as indicated by the lack of significance for the log-likelihood ratio. The only significant log-likelihood ratio was for SUCCESS in $1998(p=0.047)$ and FEMRET in 1999 ( $p=0.003$ ); however, examination of prediction success tables for these two regressions indicated the model was a poor predictor of these dependent variables. Also, model fit for these dependent variables in alternate years did not corroborate the model fit for these dependent variables. Note that sample sizes are low in many cases for MALERET, MALEREC, FEMRET, and FEMREC, and consequently the regression statistics are suspect. 
Table 14. Logistic regression statistics.

\begin{tabular}{|c|c|c|c|c|c|c|}
\hline \multirow[b]{3}{*}{$\begin{array}{l}\text { Dependent } \\
\text { Variables* }\end{array}$} & \multicolumn{6}{|c|}{ Independent Variables } \\
\hline & \multicolumn{2}{|c|}{ MILACT } & \multicolumn{2}{|c|}{ ROAD(CLASS) } & \multirow[b]{2}{*}{$\begin{array}{l}\text { Log-likelihood } \\
\text { ratio ( } p \text {-value) }\end{array}$} & \multirow[b]{2}{*}{$N$} \\
\hline & t-ratio & $p$-value & t-ratio & $p$-value & & \\
\hline \multicolumn{7}{|l|}{1997} \\
\hline SUCCESS & 0.015 & 0.988 & 0.049 & 0.961 & $0.004(0.998)$ & 19 \\
\hline BREEDING & -0.587 & 0.557 & -1.847 & 0.065 & $5.467(0.065)$ & 24 \\
\hline MALERET & 0.031 & 0.976 & 0.415 & 0.678 & $1.976(0.372)^{\star \star}$ & 9 \\
\hline MALEREC & -0.006 & 0.995 & -0.586 & 0.558 & $1.421(0.492)^{*}$ & 4 \\
\hline FEMRET & 0.030 & 0.976 & 0.457 & 0.648 & $1.100(0.577)^{\star \star}$ & 12 \\
\hline FEMREC & 0.016 & 0.988 & -0.023 & 0.982 & $4.499(0.105)^{\star \star}$ & 4 \\
\hline \multicolumn{7}{|l|}{1998} \\
\hline SUCCESS & 1.621 & 0.105 & -0.380 & 0.704 & $6.120(0.047)$ & 29 \\
\hline BREEDING & 0.953 & 0.341 & 1.784 & 0.074 & $3.965(0.138)$ & 51 \\
\hline MALERET & 0.032 & 0.974 & -0.352 & 0.725 & $1.560(0.458)^{\star \star}$ & 24 \\
\hline MALEREC & -0.986 & 0.324 & 0.933 & 0.351 & $2.330(0.312)$ & 12 \\
\hline FEMRET & 0.034 & 0.973 & -0.002 & 0.999 & $7.191(0.027)^{\star \star}$ & 14 \\
\hline FEMREC & -1.343 & 0.179 & 0.920 & 0.358 & $3.364(0.186)$ & 14 \\
\hline \multicolumn{7}{|l|}{1999} \\
\hline SUCCESS & -0.027 & 0.978 & 0.851 & 0.395 & $0.794(0.627)$ & 39 \\
\hline BREEDING & 0.950 & 0.342 & 1.302 & 0.193 & $2.563(0.278)$ & 51 \\
\hline MALERET & -1.193 & 0.233 & -0.333 & 0.739 & $1.564(0.458)$ & 23 \\
\hline MALEREC & 1.461 & 0.140 & 0.525 & 0.600 & $4.067(0.131)$ & 12 \\
\hline FEMRET & 0.582 & 0.560 & -1.740 & 0.082 & $11.337(0.003)$ & 17 \\
\hline FEMREC & -0.544 & 0.586 & 1.181 & 0.238 & $3.474(0.176)$ & 14 \\
\hline
\end{tabular}

* Dependent variables $=$ Constant + MILACT + ROAD. SUCCESS $=$ fledging at least one young given presence of breeding pair. BREEDING = presence of breeding pair. MALERET = presence of breeding male from previous year. MALEREC = recruitment of new breeding male. FEMRET and FEMREC = female equivalent of MALERET and MALEREC variables. MILACT and ROAD are arcsine and logtransformed values, respectively. $\mathrm{N}=$ sample size.

${ }^{* *}$ Model failed to satisfy change tolerance. Log-likelihood ratio and associated p-value are suspect. 


\section{Analyses of Maneuver Training Effects}

Chapter 5 presented analyses and data summaries to select variables for analysis of maneuver training effects on RCWs relative to habitat and demographic factors. Variables were retained based on correlations among independent variables, relationship to dependent variables, sample size, and representative of factors potentially affecting RCW populations. Dependent variables retained for analysis include number of young fledged (NFLDG, Table 1 (page 14), whether young were fledged from the cluster (SUCCESS), and whether a breeding pair was present (BREEDING). Independent variables retained were presence of auxiliary birds in breeding groups (GRPN), success in fledging young in the preceding year (PRSUC), principal component scores for habitat (PC1, PC2, and PC3), level of military activity observed at cluster site (MILACT), local density of active clusters (ISOL), number of useable cavities per cluster (NCAV), and proximity of cluster to nearest maintained road (LIOROAD).

Analyses of the relationships between dependent and independent variables were performed using multiple linear regression approaches (GLM and logistic). In a recent review, MacNally (2000) discusses the potential pitfalls in ecological applications of this approach, particularly in predictive versus causal inferences of the results. The results reported here present the most parsimonious predictive relationships between the dependent and independent variables. These relationships are used to evaluate the relative importance of the independent variables as predictors of observed variance in the independent variables.

The dependent variables SUCCESS and BREEDING are class variables with two levels (Yes or No). Logistic regression was used to evaluate predictive models for SUCCESS and BREEDING. Results of model exploration were satisfactory in identifying any combination of significant predictor variables for SUCCESS or BREEDING. For both dependent variables, models either failed to satisfy change tolerance, or in stepwise procedures (backward elimination) all independent variables except the constant were removed due to lack of significance. These results suggest that the independent variables or combination of variables are not reliable predictors of the presence of a breeding pair or success of breeding pairs in fledging young.

Multiple regression to evaluate predictive models for number of young fledged (NFLDG) produced more satisfying results. Table 15 shows results for multiple 
linear regression for the full model (all independent variables entered). $R^{2}$ for the full model ranged from 0.404 in 1999 to 0.723 in 1998. The regression sumof-squares was significant for 1998 ( $F=4.361, p=0.006)$. However, as MacNally (2000) points out, with many independent variables in the model, high $\mathrm{R}^{2}$ values can be a mathematical artifact of the proportion of the number of variables to cases. Also the purpose is to identify those variables that are the best predictors of the number of young fledged.

Table 15. Results of multiple linear regression for NFLDG for all independent variables entered as model terms.

\begin{tabular}{|l|l|l|l|}
\hline Year & $\mathbf{R}^{\mathbf{2}}$ & $\mathbf{F}$ & $\mathbf{P}$ \\
\hline 1997 & 0.503 & 0.674 & 0.715 \\
\hline 1998 & 0.723 & 4.361 & 0.006 \\
\hline 1999 & 0.404 & 1.816 & 0.117 \\
\hline
\end{tabular}

To evaluate the most parsimonious model for prediction of number of young fledged, a stepwise regression (backward elimination) was performed. Criteria for variable removal was $p=0.15$. Again MacNally (2000) cautions about the potential to retain "spurious" variables based on p-values. However, in this analysis, model results from different years can be considered an independent cross-validation of model results.

Table 16 shows results of stepwise regression for each of the years in this study. For each year variables are ordered, based on order of removal and significance values of final variables retained. Note that although the stepwise procedure converges on slightly different combinations of predictor variables depending on the year, the relative order in which variables are retained is fairly consistent among years, particularly among those most likely to be retained in the final variables. GRPN, PC3, and PRSUC were among the top three variables in at least 2 of the 3 years. The only other variable occurring among the top three was ISOL in one year, 1998. PRSUC in 1998 was fourth. Also note that MILACT was in the bottom three (variables with least significance) in all years. 
Table 16. Comparison of relative significance of regression coefficients of independent variables in stepwise regression (GLM) for number of young fledged.

\begin{tabular}{|l|l|l|l|}
\hline & $1997^{*}$ & 1998 & 1999 \\
\hline Most significant & PRSUC $^{* *}$ & GRPN $^{* *}$ & GRPN $^{* *}$ \\
\hline & GRPN & PC3 $^{* *}$ & PC3 $^{* *}$ \\
\hline & PC3 & ISOL $^{* *}$ & PRSUC $^{* *}$ \\
\hline & L10ROAD & PRSUC & PC2 \\
\hline & PC2 & PC2 & NCAV \\
\hline & ISOL & PC1 & ISOL \\
\hline & MILACT & NCAV & MILACT \\
\hline & PC1 & MILACT & PC1 \\
\hline Least significant & NCAV & L10ROAD & L10ROAD \\
\hline
\end{tabular}

*Relative significance is shown for all 3 years. For each year, variables are ordered from most significant regression coefficient (more likely to be retained in stepwise procedure) to least significant (most likely to be removed in stepwise procedure).

${ }^{* *}$ Identifies variables retained after completion of stepwise elimination. Criterion for variable elimination was $p=0.15$.

The most parsimonious model will identify the fewest model terms that will significantly and most consistently account for observed variance in the number of young fledged. Based on the results above, models with the independent variables GRPN, PRSUC, and PC3 were compared for the full model including all model terms and all subsets of the full model with two model terms. Table 17 shows results for these models. Regression sum-of-squares was significant in all years for the models GRPN + PRSUC and PC3 + PRSUC. The regression sumof-squares was significant in 1998 and 1999 for the full model and GRPN + PC3, but were not significant in 1997, although the full model approached significance $(p=0.073)$.

Table 17. Comparison between complete multivariate regression model (GLM)* results for NFLDG with all possible submodels with two independent variables.

\begin{tabular}{|l|l|l|l|l|l|l|l|l|l|}
\hline & \multicolumn{3}{|c|}{1997} & \multicolumn{3}{c|}{1998} & \multicolumn{3}{|c|}{1999} \\
\hline $\begin{array}{l}\text { Model } \\
\text { Terms }\end{array}$ & $\mathrm{R}^{2}$ & $\mathrm{~F}$ & $\mathrm{P}$ & $\mathrm{R}^{2}$ & $\mathrm{~F}$ & $\mathrm{P}$ & $\mathrm{R}^{2}$ & $\mathrm{~F}$ & $\mathrm{P}$ \\
\hline $\begin{array}{l}\text { GRPN+ } \\
\text { PC3+ } \\
\text { PRSUC }\end{array}$ & 0.247 & 2.631 & 0.073 & 0.554 & 8.700 & 0.001 & 0.364 & 5.723 & 0.003 \\
\hline $\begin{array}{l}\text { GRPN+ } \\
\text { PC3 }\end{array}$ & 0.022 & 0.299 & 0.744 & 0.566 & 14.977 & 0.000 & 0.303 & 7.156 & 0.003 \\
\hline $\begin{array}{l}\text { GRPN+ } \\
\text { PRSUC }\end{array}$ & 0.219 & 3.503 & 0.046 & 0.439 & 8.615 & 0.002 & 0.294 & 6.470 & 0.004 \\
\hline $\begin{array}{l}\text { PC3+ } \\
\text { PRSUC }\end{array}$ & 0.298 & 5.953 & 0.007 & 0.247 & 4.096 & 0.029 & 0.261 & 5.989 & 0.006 \\
\hline
\end{tabular}

* Complete GLM model is NFLDG = constant + GRPN + PC3 + PRSUC. 
Examination of $\mathrm{R}^{2}$ values for the full model and submodels, shows that the full model had consistently higher $\mathrm{R}^{2}$ values in all years except PC3 + PRSUC in 1997 ( $R^{2}=0.298$ versus 0.247 for full model) and slightly higher values for GRPN +PC3 in $1998\left(R^{2}=0.566\right.$ versus 0.554 for full model $)$. The results presented in Table 17 suggest that of all the predictor variables considered in this chapter the model NFLDG $=$ GRPN + PC3 + PRSUC presents the best balance between accounting for the largest amount of variance in NFLDG and achieving significance for the regression. Significance of the model terms GRPN and PRSUC for NFLDG is consistent with univariate results presented in Chapter 5. It is also of interest that PC3 loads most heavily on variables related to burning regime. Specifically, the results here suggest a relationship of NFLDG with higher burn frequency and interval to most recent burn (as suggested by PC3).

Note, however, that this three-term model does not account for a large proportion of the variance in NFLDG. The model terms retained in this model (GRPN, PC3, and PRSUC) also reinforces that these models are predictive and do not illustrate causal relationships. It is intuitive that if a cluster is successful in fledging young in the previous year (PRSUC) that the likelihood of having auxiliaries (GRPN) increases in the following year. The fact that young were fledged in a previous year should not be interpreted as the cause of increased production of young in the current year. Rather the predictive relationship of PRSUC to NFLDG likely reflects a relationship of PRSUC to the presence of auxiliaries in the current year (GRPN) and longer tenure of the breeding adults in the cluster. Although the relationship is not exceedingly strong, correlation between PRSUC and GRPN are among the highest observed among the independent variables in 1998 (Spearman rank coefficient $=0.446$ ) and 1999 (Spearman rank coefficient $=$ $0.502)$. 


\section{Determining Population Level Effects of Military Disturbance}

Although only a few RCW clusters on Fort Stewart appear to be subject to relatively high levels of human activity at present, this situation could change after the implementation of the revised 1996 "Management Guidelines for RCWs on Army Installations," which are anticipated to be in effect by 2001 . The question that will be addressed in this section is: What hypothetical effects on Redcockaded Woodpecker (RCW) population viability would accrue, if various proportions of RCW breeding habitat on Fort Stewart were subject to high levels of potentially disturbing human activity? An answer to this question will be attempted by performing a population viability analysis, using the data on military-civilian activities, and on RCW nest productivity, that were collected at Fort Stewart RCW cluster sites during this study.

\section{Materials and Methods}

The procedure for estimating the potential effects of military-civilian activities on the Fort Stewart RCW population was as discussed in the following paragraphs.

\section{Classification of Cluster Sites by Military Activity Levels}

First, 51 cluster sites having at least 2 years of observation data on military and civilian activity were identified. From these, a subset of 24 clusters, each with 3 years of breeding attempts (breeding pair with nest present) recorded per cluster, was established as the data set for the present analysis. This data set was expressed as a bivariate plot, with each point representing a cluster's 2- or 3year (depending on available data) mean proportion of observation periods with civilian (mean CIVACT) vs. military (mean MILACT) activity. For definitions of MILACT and CIVACT, see Table 1 (page 14). The clusters were then divided, on the basis of the bivariate plot, into classes of "high" vs. "low" military-civilian activity potentially disturbing to RCWs on Fort Stewart. "High" activity classes included those clusters where the proportion of observation periods with civilian activity was greater than 0.10 , and the proportion of observation periods with observed military activity was greater than 0.15 . 


\section{Fledgling Production in Each Activity Level}

The yearly descriptive statistics for "nest success" (proportion of nests for which SUCCESS $=1$ ), and for the mean number of fledglings produced (mean NFLGD) per successful nest (denoted here as "Fledglings | Successful"), were calculated for the "low" and "high" disturbance activity classes. For definitions of NFLGD and SUCCESS, see Table 1 . The means of these yearly statistics were tested for difference between activity classes by t-tests, using SAS/STATâ PROC TTEST (SAS Institute Inc. 1989).

Next, the means for nest success and fledglings per successful nest, along with their temporal (over 3 years) and sampling error variances and standard deviations, were calculated for each disturbance activity class of RCW clusters. Temporal and sampling variances (and standard deviations) of these variables were calculated using the variance partitioning method described in Stewart-Oaten, Murdoch, and Walde (1995). These statistics were taken to represent the population in pure "low" vs. pure "high" disturbance activity habitats. Effective sample sizes for the low and high activity groups were taken to be the total number of observations upon which the analyses were based. These were 21 clusters $\times 3$ years $=63$ cluster-years for the "Iow" activity class, and a corresponding 3 clusters $\times 3$ years $=9$ cluster-years for the "high" activity class.

\section{Hypothetical Disturbance Scenarios}

Weighted averages of the statistics from these "pure" activity classes were used to estimate nest productivity statistics (and their effective sample sizes) for nine hypothetical disturbance scenarios, representing reproductive productivity on Fort Stewart if different proportions of the RCW habitat were in the "high" disturbance activity category. These scenarios allow comparison of the observed disturbance levels on Fort Stewart in the context of the full range of possible disturbance scenarios. For given statistics from "high" vs. "low" activity classes,

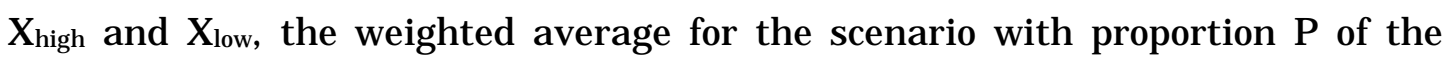
habitat in the "high" activity category was calculated as:

Weighted Average of $X=P X_{\text {high }}+(1-P) X_{\text {low }}$

Effective sample sizes for each scenario were also calculated as weighted averages, truncated to their integer values. 


\section{Population Viability Analysis Using PVAvES 1.0}

Finally, the statistics for these nine scenarios were entered as input data to program PVAvES 1.0, a population viability program developed at the U.S. Army Engineer Research and Development Center/Construction Engineering Research Laboratory (ERDC/CERL) to estimate the risk of extinction for threatened and endangered avian populations on military lands. The algorithms of the PVAvES program are described in a previous technical report (Melton et al. 2001). Derivations of many of the input parameter values used in the present study, calculated from Fort Stewart data, are described there. Input parameter derivations from data, other than those noted above, will not be described in detail unless the values used here differed from those of the previous report.

The Appendix shows an example of an input data file read by PVAvES at the beginning of program operation. Parameter values from the Fort Stewart RCW population used in this study are as follows:

1. Parameters with the same values in all disturbance scenarios:

a. The initial population size (Appendix, input \# 7) is set here to the known breeding female population size at the end of year 1999, which was 165 breeding females (i.e., females known to have made at least 1 nesting attempt that year).

b. The maximum carrying capacity (input \# 8) for the Fort Stewart RCW population is set to its estimated value of 506 breeding females under the most recent draft version of the Fort Stewart Endangered Species Management Plan.

c. The pseudoextinction threshold (input \# 9), below which a population is considered effectively extinct, was set to 5 breeding females.

d.The target population size (input \# 10) which is desirable to equal or exceed as a criterion of successful management, was set to be 250 breeding females, following the USFWS guidelines delineated in the RCW recovery plan.

e. The maximum possible seasonal fecundity (input \# 17) was set to the maximum observed size of 4 nestlings (of both sexes).

f. The probability that a fledgling is female (input \# 18) was set to equal 0.5 , following the observed fledgling sex ratio of $1: 1$. 
g. The mean fledgling female survival rate, and its associated temporal and sampling standard deviations (inputs \# 19, 20, 21).

h. The mean adult female survival rate, and its associated temporal and sampling standard deviations (inputs \#22, 23, 24).

i. The recurrence rates, and the effects on survival and fecundity, of hurricane catastrophes (inputs \# 30 through 44) are somewhat different than those in the previous report, although their derivations are basically the same.

2. Parameters whose values varied among disturbance scenarios:

a. The effective sample size for each disturbance scenario (input \#3).

b. The mean proportion of successful nests, and its associated temporal and sampling standard deviations (inputs \#11, 12, 13).

c. The mean number of fledglings | successful nest, and its associated temporal and sampling standard deviations (inputs \#14, 15 16).

The latter parameters, whose values varied among disturbance scenarios, are the reproductive statistics previously discussed above.

The previous study using PVAvES (Melton et al. 2001) showed that the omission of the effects of hurricane catastrophes, in a population viability analysis of the Fort Stewart RCW population, results in a considerable underestimation of the likelihood of extinction. Therefore, hurricane catastrophes were included in the present analyses. The parameters for hurricane occurrence rates, and hurricane effects on survival and fecundity, in the present analysis were somewhat different than those used in the previous study. The parameter input values, in the present study, for the recurrence rates of hurricanes (inputs \#30, 33, 36, 39, 42) were based on the estimated recurrence rates of Saffir-Simpson category I, II, III, IV, and V strength hurricanes for Fort Stewart (Hooper and McAdie 1995). The parameter values for percent reduction of survival rates, and population carrying capacity, by Category III hurricanes (inputs \# 37, 38) were taken from the documented effects of hurricane Hugo on the RCW population at Francis Marion National Forest in North Carolina (Watson et al. 1995). Hugo was a category III hurricane when it hit the population. In the absence of better information, comparable parameter values for categories I , II, IV, and V hurricanes were extrapolated from the parameter values for category III hurricanes. This was done by assuming that their values varied in direct proportion to the 
square of the threshold maximum sustained wind speeds for each category as given in Hooper and McAdie (1995), i.e., varied in proportion to the wind's kinetic energy. All parameter values for PVAvES catastrophe levels 6-10 (inputs \# 45-59) were set equal to 0.

Two sets of PVAvES outputs were reported in this study, for each disturbance scenario. One set of outputs included the median probabilities of pseudoextinction within less than or equal to 10 years, 20 years, and 100 years. Medians, rather than means, were reported because the underlying distributions were typically highly skewed and/or bimodal. The second set of outputs included the probabilities that the population should be classed as VULNERABLE, as ENDANGERED, and as CRITICAL, using the definitions:

VULNERABLE: The probability of pseudoextinction within 100 years $\geq 0.1$

ENDANGERED: The probability of pseudoextinction within 20 years $\geq 0.2$

CRITICAL: The probability of pseudoextinction within 10 years $\geq 0.5$.

These definitions are taken from the IUCN extinction risk criteria, as proposed in Mace and Stuart (1994).

\section{Results}

\section{Classification of Cluster Sites by Military Activity Levels}

The bivariate distribution of clusters based on observed military and civilian activity is presented in Figure 12 . This activity includes all civilian and military activity as described in Tables 2 through 5, including both vehicle and dismounted personnel activity. Most clusters did not show exceedingly high levels of either kind of activity. However, three clusters (clusters \# 7, 47, and 57) could be readily identified as having unambiguously high relative levels of military and (to a lesser degree) civilian activity. These three clusters were designated as "high" activity clusters, and the rest designated the "Iow" activity clusters. This visually patent, but somewhat arbitrary, classification corresponds to a post hoc criterion for each "high" activity cluster site of mean MILACT $>0.2$, and mean CIVACT $>0.1$. 


\section{Fledgling Production in Each Activity Level}

Nest productivity statistics for each activity class and year, along with their standard errors and sample sizes, are shown in Table 18. The 3-year means of the mean proportion of successful nests (Table 19) showed no significant difference between activity classes at the .05 level ( $t=-0.6565$, $d f=4, p=0.5473$ ). The 3-year means of the mean number of fledglings | successful nest (Table 19) did differ significantly, at the $5 \%$ level, between activity classes $(t=-4.1587$, df $=$ $4, p=0.0142$ ).

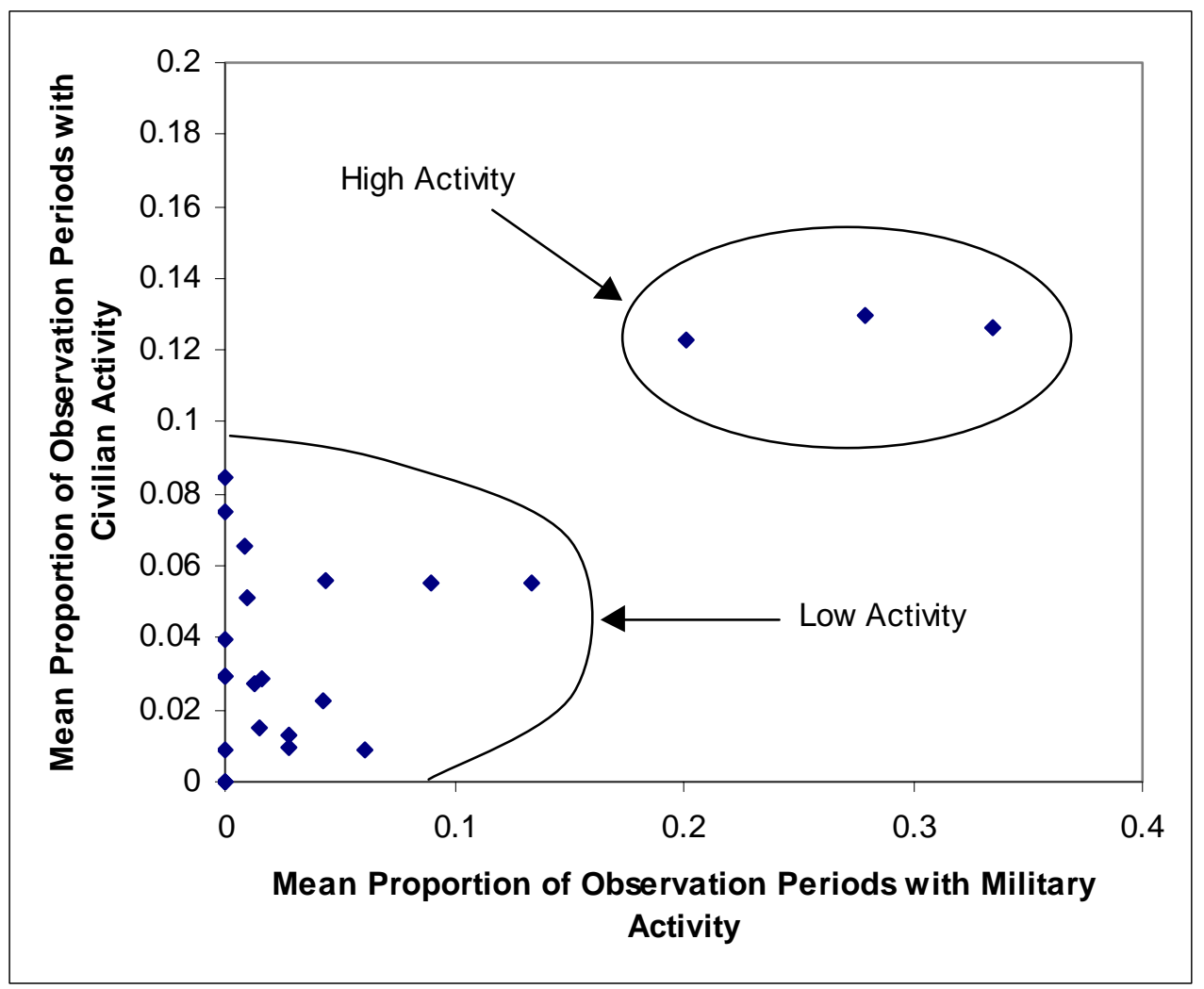

Figure 12. Classification of Red-cockaded Woodpecker clusters used in the population viability analysis, based on 2- or 3-year mean levels of military and civilian activity. 
Table 18. Nest productivity summary statistics, over three years, for Red-cockaded Woodpecker clusters in "low" and "high" disturbance activity classes.

\begin{tabular}{|l|l|l|}
\hline \multicolumn{3}{|c|}{ Nest Productivity -- Descriptive Statistics } \\
\hline A) Low Activity: & \\
\hline Year & $\begin{array}{l}\text { Proportion Successful } \\
\text { Mean } \pm \text { Binomial SE (N)* }\end{array}$ & $\begin{array}{l}\text { Fledglings | Successful } \\
\text { Mean } \pm \text { SE (N) }\end{array}$ \\
\hline 1997 & $0.9048 \pm 0.0641(21)$ & $2.3158 \pm 0.1539(19)$ \\
\hline 1998 & $0.7619 \pm 0.0929(21)$ & $2.1875 \pm 0.1638(16)$ \\
\hline 1999 & $0.9047 \pm 0.0641(21)$ & $2.2105 \pm 0.1806(19)$ \\
\hline B) High Activity: & \begin{tabular}{l} 
Proportion Successful \\
\hline
\end{tabular} & Fledglings | Successful \\
Year & Mean \pm Binomial SE (N) & Mean \pm SE \\
\hline 1997 & $0.6667 \pm 0.2722(3)$ & $1.0000 \pm 0.0000(2)$ \\
\hline 1998 & $1.0000 \pm 0.0000(3)$ & $1.6667 \pm 0.3333(3)$ \\
\hline 1999 & $0.6667 \pm 0.2722(3)$ & $1.5000 \pm 0.5000(2)$ \\
\hline
\end{tabular}

* "SE" denotes standard error. "N" denotes sample size.

Table 19. Estimated PVAvES nest productivity parameters, calculated from the RCW clusters in "low" and "high" disturbance activity classes.

\begin{tabular}{|l|l|l|}
\hline & \multicolumn{2}{l|}{$\begin{array}{l}\text { Military Disturbance } \\
\text { Category: }\end{array}$} \\
\hline Estimated Nest Productivity Parameter & Low & High \\
\hline & & \\
\hline Mean Proportion Successful & 0.8571 & 0.7778 \\
\hline Temporal SD (standard deviation) & 0.0345 & 0.0000 \\
\hline Sampling SD & 0.0749 & 0.2222 \\
\hline & & \\
\hline Mean Fledglings | Successful & 2.2379 & 1.3889 \\
\hline Temporal SD & 0.0000 & 0.0000 \\
\hline Sampling SD & 0.1665 & 0.3469 \\
\hline & & \\
\hline Effective Sample Size & 63 & 9 \\
\hline
\end{tabular}

\section{Hypothetical Disturbance Scenarios}

Table 19 shows the 3-year means of the means in Table 18, along with their temporal (over 3 years) and sampling error standard deviations, and associated effective sample sizes. Table 20 presents the nest productivity parameter values, and effective sample sizes, for all 9 hypothetical disturbance scenarios used as inputs to the PVAvES program. Scenario values were calculated as weighted averages of the values for "low" and "high" disturbance categories shown in Table 19. 
Table 20. Parameterization of nine hypothetical disturbance scenarios, derived as weighted averages of the parameter estimates in Table 19.

\begin{tabular}{|l|l|l|l|l|l|l|l|l|l|l|}
\hline & \multicolumn{7}{|l|}{} \\
& \multicolumn{7}{|l|}{$\begin{array}{l}\text { Military Disturbance Scenarios: } \\
\text { Cypothetical proportion of RCW habitat in High Military Disturbance }\end{array}$} \\
\hline $\begin{array}{l}\text { Nest Productivity } \\
\text { Parameter }\end{array}$ & $\begin{array}{l}\text { PVAvES } \\
\text { Input ID }\end{array}$ & 0 & 0.125 & 0.250 & 0.375 & 0.500 & 0.625 & 0.750 & 0.875 & 1 \\
\hline $\begin{array}{l}\text { Mean Proportion Suc- } \\
\text { cessful }\end{array}$ & $\# 11$ & 0.8571 & 0.8472 & 0.8373 & 0.8274 & 0.8175 & 0.8075 & 0.7976 & 0.7877 & 0.7778 \\
\hline $\begin{array}{l}\text { Temporal SD (standard } \\
\text { deviation) }\end{array}$ & $\# 12$ & 0.0345 & 0.0302 & 0.0258 & 0.0215 & 0.0172 & 0.0129 & 0.0086 & 0.0043 & 0.0000 \\
\hline Sampling SD & $\# 13$ & 0.0749 & 0.0933 & 0.1118 & 0.1302 & 0.1486 & 0.1670 & 0.1854 & 0.2038 & 0.2222 \\
\hline $\begin{array}{l}\text { Mean Fledglings } \\
\text { Successful }\end{array}$ & $\# 14$ & 2.2379 & 2.1318 & 2.0257 & 1.9195 & 1.8134 & 1.7073 & 1.6012 & 1.4950 & 1.3889 \\
\hline Temporal SD & $\# 15$ & 0.0000 & 0.0000 & 0.0000 & 0.0000 & 0.0000 & 0.0000 & 0.0000 & 0.0000 & 0.0000 \\
\hline Sampling SD & $\# 16$ & 0.1665 & 0.1890 & 0.2116 & 0.2342 & 0.2567 & 0.2793 & 0.3018 & 0.3244 & 0.3469 \\
\hline Effective Sample Size & $\# 3$ & 63.00 & 56.25 & 49.50 & 42.75 & 36.00 & 29.25 & 22.50 & 15.75 & 9.00 \\
\hline
\end{tabular}

\section{Population Viability Analysis using PVAvES 1.0}

Figure 13 illustrates the relationships of the median probabilities of pseudoextinction within 100 years, 20 years, and 10 years, to the proportion of RCW habitat in the "high activity" category. The median probability of pseudoextinction within 100 years showed a sigmoid relationship to the proportion of "high" activity habitat (Figure 13A), increasing steeply for proportions greater than 25 percent A probability of pseudoextinction, within 100 years, of 100 percent could not be ruled out (based on 95 percent confidence intervals) for proportions of "high" activity habitat greater than 50 percent The median probability of pseudoextinction within 20 years (Figure 13B) was generally low, but increased steeply when the proportion of "high" activity habitat was greater than 75 percent. The median probability of pseudoextinction within 10 years (Figure $13 \mathrm{C}$ ) was very low for all disturbance scenarios.

Figure 14 illustrates the relationships of the probabilities that the Fort Stewart RCW population should be classified by the risk categories VULNERABLE, ENDANGERED, and CRITICAL, to the proportion of RCW habitat in the "high activity" category. The probability that the class =VULNERABLE (Figure 14A) was significantly greater than 0 (based on 95 percent confidence intervals) even when the proportion of "high" activity habitat was 0 . It showed a concave increase with increasing proportions of "high" activity habitat, and probabilities of 90 percent or more could not be ruled out for proportions of "high" activity habitat greater than 75 percent. The probability that the class = ENDANGERED (Figure 14B) was low when the proportion of "high" activity habitat was 0 , and 
showed a convex increase with increasing proportions of "high" activity habitat. It was significantly greater than 0 for proportions of "high" activity habitat greater than or equal to 50 percent. The probability that the class $=$ CRITICAL (Figure 14C) was very low for all disturbance scenarios. 

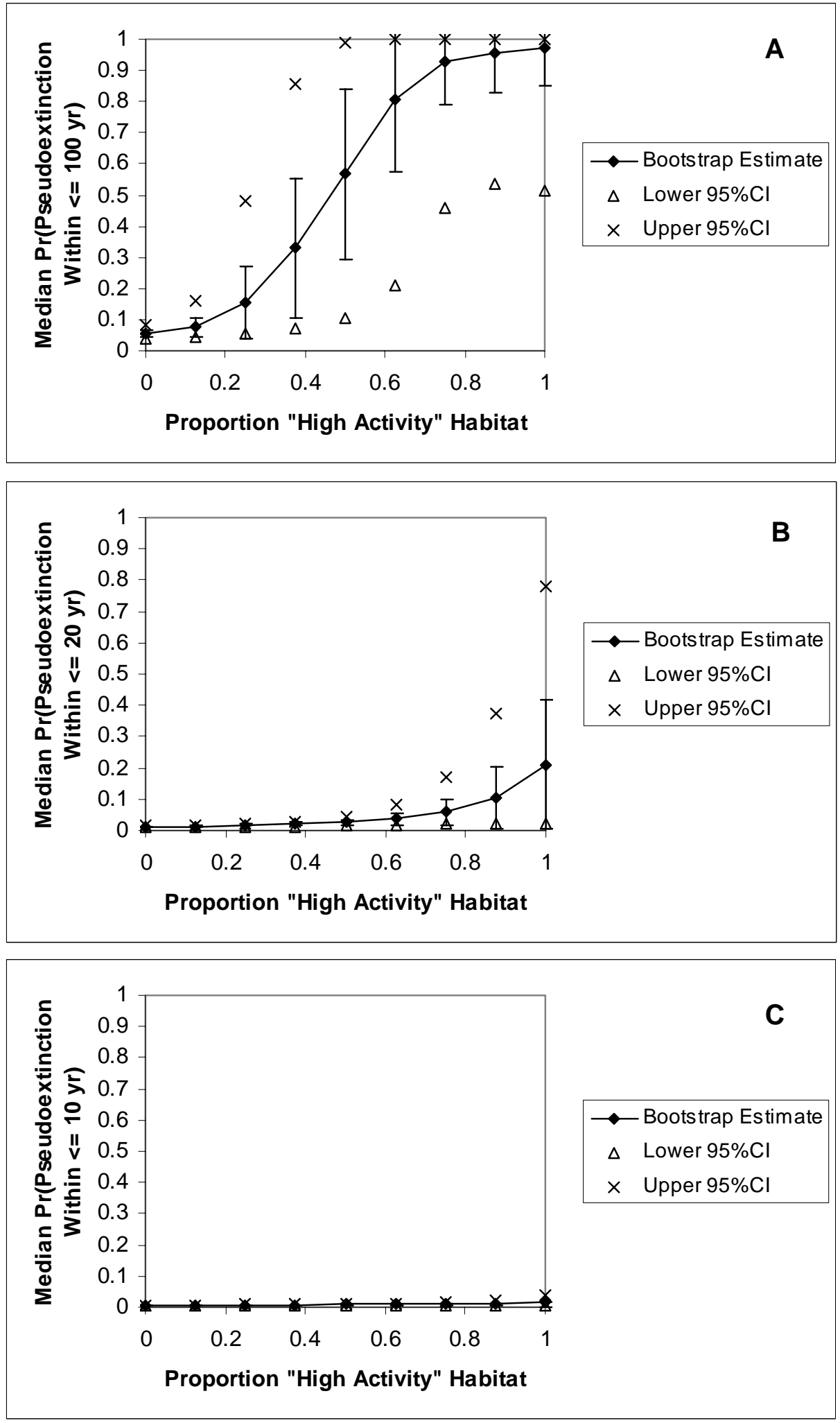

A, within 100 years; B, within 20 years; and C, within 10 years, when different hypothetical proportions of the habitat are assumed to be "high activity" habitat. Error bars denote 1 bootstrap standard error. "Cl" denotes bootstrap percentile confidence interval.

Figure 13. Estimated pseudoextinction probabilities for the Red-cockaded Woodpecker population on Fort Stewart. 

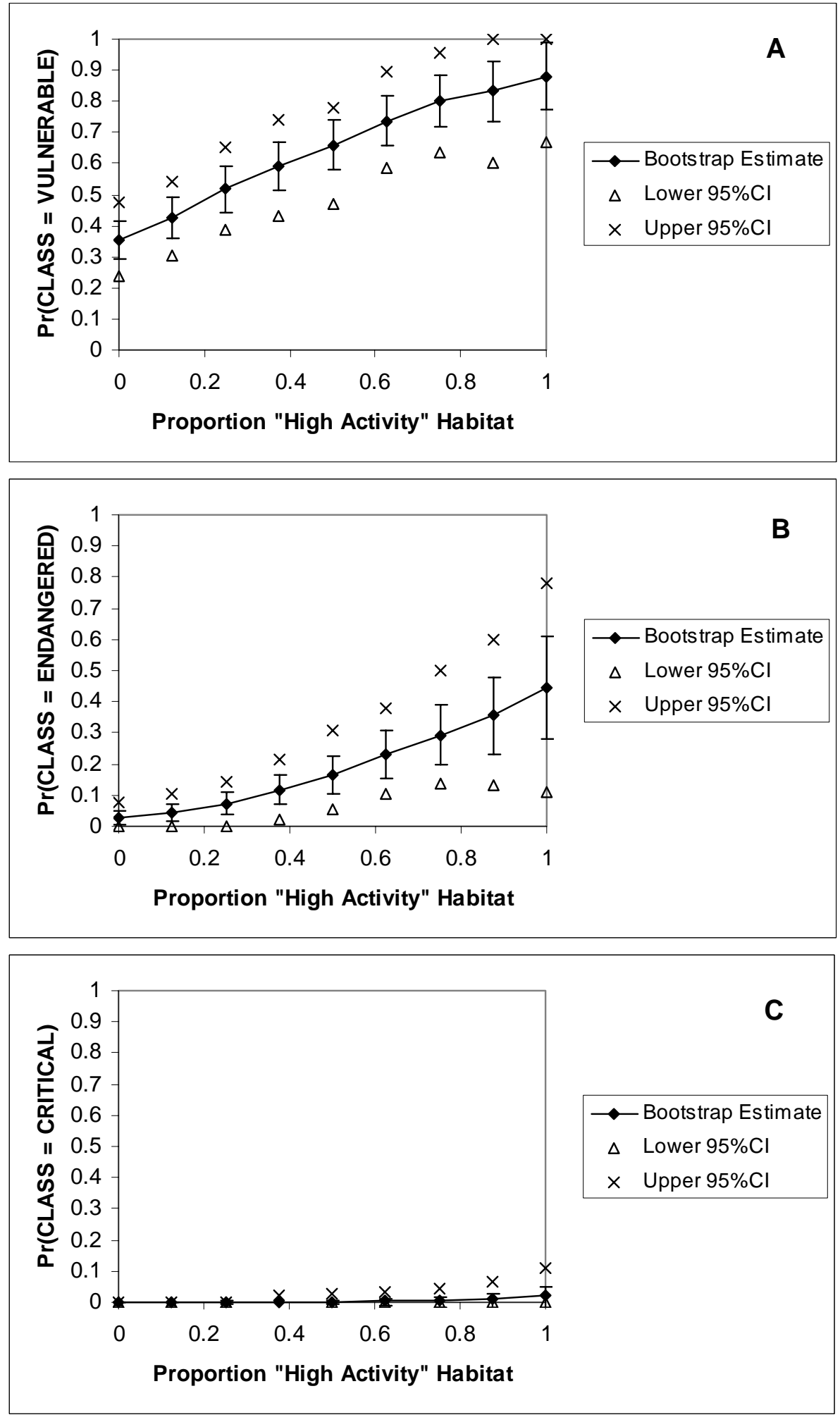

A, VULNERABLE; B, ENDANGERED; and C, CRITICAL when different hypothetical proportions of the habitat are assumed to be "high activity" habitat. Error bars denote 1 bootstrap standard error. "Cl" denotes bootstrap percentile confidence interval.

Figure 14. Estimated probabilities that the Red-cockaded Woodpecker population on Fort Stewart should be classified as vulnerable, endangered, and critical. 


\section{Discussion}

Division of the RCW cluster data set into "high" and "low" activity classes proved to be a useful device for the present population viability analysis, allowing creation of the nine hypothetical disturbance activity scenarios. Only 3 clusters out of the 24 shown in Figure 12 (and, in fact, only 3 out of all 51 clusters with 2 or more years with military-civilian activity observations) stood out as "high" activity clusters - a very small sample size. However, the fact that nest success, and fledglings | success, were lower in the "high" than in the "low" activity clusters (significantly so for fledglings | success) suggests that some correlate of military or civilian activity may indeed reduce nest productivity in these "high" activity clusters. Thus the question "What would happen in terms of risk to the population if more RCW habitat on the installation were subject to "high" activity levels?" is a logical one to ask.

When interpreting the results presented here, it is best to keep in mind that the estimates reported for the population viability parameters are not necessarily conservative estimates. Although demographic, environmental, catastrophic, and sampling variation in life-history parameters are incorporated into the PVAvES model, no model is likely to include all potential sources of variation, and any such unaccounted sources would most likely tend to further reduce population viability estimates. Also, survival rates of breeding females are, in the present study, assumed to be the same for "low" and "high" activity habitats. Therefore, the reported parameter estimates should not be taken too literally. Comparisons among the hypothetical disturbance scenarios, however, are more likely to be valid.

With this caveat in mind, the present results suggest that if a substantial proportion (e.g., over 50 percent of RCW habitat on the installation were subject to "high" military-civilian activity, this would have a significant negative effect on the viability of the Fort Stewart RCW population. Such a condition would increase the population's probability of extinction (especially in the 100-year long term), and concomitantly increase the likelihood that the population should be classified as VULNERABLE and also as ENDANGERED.

The present proportion of RCW habitat on Fort Stewart that is subject to "high" military-civilian activity is not known with certainty. Out of the sample of 51 cluster sites having at least 2 years of observation data on military and civilian activity, only 3 clusters (the "high" activity clusters shown in Figure 12), or 6 percent of the total sample, had mean values of MILACT >0.2. If we take a value of less than 10 percent to roughly represent the proportion of "high" activity RCW breeding habitat on Fort Stewart, then the results suggest that the 
viability of the RCW population is, at present, essentially unaffected by "high" levels of military activities. Whether this situation will continue, when training restrictions are revised in accordance with the 1996 RCW management guidelines, needs to be monitored.

Even if all of the RCW breeding habitat on the installation were in the "low" activity class, Figure 14A shows that the Fort Stewart RCW population would have a 24 to 48 percent chance that its viability status should be considered VULNERABLE, given the model's assumptions and the present input data. The population, while not presently in extremis, should not be considered safe from extinction within the next 100 years, even under a low military-civilian disturbance regime. Continued monitoring, and management, of the Fort Stewart RCW population appears to be warranted. 


\section{Conclusions and Recommendations}

\section{Fort Stewart Results}

Results from this study on Fort Stewart, Georgia during 1997-1999 indicate that demographic factors (e.g., group size and prior reproductive success) have more effect on RCW reproductive success than habitat and/or disturbance from human activities. Observations of human activity at RCW sites suggest that the probability of disturbance from military training activities in clusters is relatively low in the majority of RCW cluster sites on Fort Stewart. However, data from a small number of clusters in high-traffic areas on the installation suggest that disturbance exceeding certain levels of activity could be detrimental to RCW reproductive success. Population viability modeling indicates that at the present time potential disturbance effects in this small proportion of the population have negligible effect on the viability of the F ort Stewart RCW population.

These results indicate that current Fort Stewart management practices are successfully mitigating variance in reproductive parameters attributable to effects of habitat. Several factors in previously published studies (Carter, Walters, and Doerr 1995; DeLotette, Epting, and DeMuth 1995) have related cluster occupancy and reproductive success to numbers of available cavities and midstory encroachment. This study did not find any significant association between these habitat factors and cluster occupancy or reproductive success in monitored clusters. These findings are not surprising given the aggressive habitat management in practice at Fort Stewart over the past several years. These results indicate that aggressive management can minimize habitat as a limiting factor on RCW populations. Continuing these management practices in all primary and supplemental clusters will continue to reduce potential limits on RCW populations due to habitat features.

Demographic factors (group size and prior reproductive success) have the most discernible relationship to RCW reproductive success on Fort Stewart. Demographic limitations on populations are more difficult to ameliorate through direct management intervention than habitat management practices. However, providing the necessary conditions such as adequate cavity availability and minimizing cluster isolation will be supportive of desirable demographic profiles in the F ort Stewart population. 
During the time period of this study (1997-1999) training restrictions in effect on Fort Stewart were in accordance with the 1994 "Management Guidelines for RCWs on Army Installations." These restrictions essentially prohibited mechanized maneuver training activities within 200 feet of cavity or start trees except on maintained roads and trails. Adherence to these restrictions was reflected in observations of training activity in proximity to RCW clusters during 1997-1999. The minimal effect of maneuver training activities during this period was observed in the context of operations under these training restrictions.

Prior to the 2001 RCW breeding season, Fort Stewart will implement its installation Endangered Species Management Plan (ESMP) in accordance with the revised 1996 "Management Guidelines for RCWs on Army Installations." Restrictions on maneuver training operations in proximity to RCW clusters will be significantly reduced under the implemented ESMP. Military vehicle traffic will be unrestricted within cluster sites except within a 50-ft buffer around cavity and start trees.

This study provides the baseline data necessary to evaluate potential effects of implementing revised training restrictions on RCW populations on Fort Stewart, Georgia. This study identified monitored clusters that consistently receive higher levels of military training. These likely will be the clusters that are at higher risk from potential effects of training under the reduced restrictions. Monitoring data collected by installation biologists in clusters with relatively high levels of training activity should be assessed annually in comparison with baseline data from the clusters during 1997-1999 and relative to clusters identified at low risk from military activity within the monitoring year. This comparison should be valid unless the Fort Stewart training mission significantly changes or distribution of training activity significantly changes.

Based on results of this study it is not recommended that intensive site-specific monitoring of training activity be continued. The bases for this recommendation are that (1) the proportion of observed training activity is relatively low, which is problematic for establishing statistical relationships between frequency of training and measures of RCW population parameters, and (2) as noted above, relative risk of exposure to training activity has been identified for monitored clusters in this study, assuming no significant change in the conduct of training operations on Fort Stewart. Use of RFMSS scheduling data is recommended to assess the overall level and distribution of training activity during the baseline years 1998 and 1999 and future years of population monitoring.

Data presented in this report show a weak association with observed training at the site level, which is likely an artifact of the overall low frequency of observed 
activity at the site level and the low "resolution" of the RFMSS scheduling variables used in analyses in this report. However, comparison of RFMSS data among years should provide an index of change in conduct of training operations on the installation.

It is recommended that site-specific monitoring of training activity should be implemented only if (1) significant negative changes in monitored population parameters are observed between data obtained during baseline years 1997-1999 and data in later years, or (2) the training mission, training intensity, or conduct of training operations on F ort Stewart significantly changes relative to scheduled activity during 1997-1999.

\section{Use in Endangered Species Risk Assessments}

Results of this study cannot be extrapolated directly to RCW populations on other military installations. Results presented here are largely dependent on the combination of habitat, demographic, and training parameters that are unique to Fort Stewart. However, the approaches taken in this study to evaluate risk to RCW populations due to training activities are applicable to other installations with RCW populations and risk assessment for other endangered species populations on military installations.

The key elements of this approach are:

2. Evaluation of exposure probability to risk factors of concern.

3. Evaluation of risk factors in context of all potential limiting factors on the population of concern.

4. Evaluation of effects of potential risk factors at the population level.

The importance of the first element is illustrated from data obtained on Fort Stewart and in many ways is the most difficult to evaluate in the context of training activities on military installations. The data for Fort Stewart clearly show that the risk of exposure to maneuver training activities on Fort Stewart is relatively low for the majority of RCW dusters. Experimental approaches can evaluate levels of effect on populations, but cannot determine potential exposure to any particular level of effect. Data for Fort Stewart suggest a level of significant effect. However, the majority of the population is not exposed to this level of effect. In the context of military operations, determining exposure risk is difficult given the dynamic and complex spatial and temporal characteristics of maneuver training activities. In this study, exposure to training activity was 
evaluated by sampling training activity at cluster sites. This approach is applicable for any risk assessment to determine probability of site-specific exposure to training activity. However, in large-scale applications, this approach is expensive, time consuming, and personnel intensive. Implementing this approach under all circumstances may allocate limited management resources away from activities that directly benefit populations of concern. In many cases exposure to risk factors from maneuver training activity may be most efficiently determined by a relative classification of risk based on expert opinion and readily available data from sources such as RF MSS scheduling data. Data from assigned risk levels can then be assessed in relation to other factors known or predicted to limit populations.

In RCWs, several factors have been identified that affect reproduction and cluster occupancy including both demographic and habitat parameters. This report analyzes potential training effects in relation to these other parameters; in fact, demographic factors were the best predictors of some aspects of RCW reproductive success and cluster occupancy. This result emphasizes the importance of installation managers being aware of the biological factors potentially limiting populations under their management concern and of tailoring monitoring plans to acquire the relevant data necessary to evaluate all potential sources of population limits. For installations implementing the Army 1996 "Management Guidelines for the Red-cockaded Woodpecker on Army Installations" estimates of critical demography parameters will be available. However, based on data availability on Fort Stewart, special emphasis should be placed on follow-up monitoring of banded populations. Emphasis on intensive habitat data collection is probably not warranted if installations are adequately implementing pre scribed burning and cavity augmentation programs. Data for Fort Stewart suggest that habitat is not an important factor in clusters with adequate midstory control and cavity availability.

The most important aspect of this study's research approach was to evaluate effects of observed population variability at the population level. Although effects at the individual level have consequences in a regulatory and compliance context, ultimately it is the effect at the population level that is significant to recovery objectives and prescriptions for protection requirements. The population viability approach presented in this report provides a probabilistic evaluation of extinction risk and population recovery potential. This is particularly relevant for installations establishing population objectives for installation ESMPs. This approach allows managers to evaluate the effect of observed demographic variability at the population level. Although evaluating installation population monitoring data in viability models cannot account for the cause of change in extinction risk or recovery objectives, significant changes 
in extinction risk or recovery objectives can be the trigger for implementing more intensive monitoring or research programs to determine causal associations. Based on results presented in this report it is recommended that installations evaluate population extinction risk and recovery probabilities for populations of management concern and formally identify change thresholds for implementing more intensive programs to identify and mitigate risk factors. 


\section{References}

Carter, J.H. III, J .R. Walters, and P.D. Doerr. 1995 "Red-cockaded Woodpeckers in the North Carolina Sandhills: a 12-year Population Study" in Red-cockaded Woodpecker: Recovery, E cology and Management, Center for Applied Studies, College of Forestry, Stephen F. Austin State U niversity, Nacogdoches, Texas.

Cottam, G., and J .T. Curtis. 1956. "The use of distance measures in phytosociological sampling." Ecology 37:451-469.

DeL otette, Roy S. Robert J . Epting, and Greg DeMuth. 1995. "A12-year Sudy of Red-cockaed Woodpecker in Central Florida" in Red-cockaded Woodpecker: Recovery, E col ogy and Management, Center for Applied Studies, College of Forestry, Stephen F. Austin State University, Nacogdoches, Texas.

Gutzwiller, K.J . and T.J . Hayden. 1997. A Literature Review of Actual and Potential Effects of Military Maneuvers On Avian Behavior, Reproduction, and Community Structure. Technical Report 97/98, U.S. Army Construction Engineering Research Laboratory (USACERL).

Hayden, T.J . 1997. Biological Assessment of the Effects Of The Proposed Revision of the 1994 "Management Guidelines for the Red-cockaded Woodpecker on Army I nstallations." USACERL Special Report 97/48/ADA 322086.

Hayden, T.J . 1999. Research Plan To Evaluate the Relationship Between Maneuver Training Activities and Red-Cockaded Woodpecker Populations and Habitats on Fort Stewart, GA. USA-CERL Special Report 99/106/ ADA 374084.

Hooper, R. G. and C. J . M cAdie. 1995. "H urricanes and the long-term management of the Redcockaded Woodpecker," pp 148-166, in Kulhavy, D.L., R.G. Hooper, and R. Costa, Eds., Redcockaded Woodpecker: Recovery, Ecology and Management. Center for Applied Studies in Forestry, Nacogdoches, Texas.

Mace, G. M. and S. N. Stuart. 1994. Draft IUCN Red List Categories, Version 2.2. Species 21-22: 13-24.

MacNally, R. 2000. "Regression and model-building in conservation biology, biogeography and ecology: The distinction between - and reconciliation of - 'predictive' and 'explanatory' models." Biodiversity and Conservation 9:655-671.

McCune, B. 1992. Multivariate analysis of ecological data. PC-ORD Version 3.2. MjM Software Design, Gleneden Beach, Oregon.

Melton, R.H., L.A. J ette, T.J . Hayden, and T.A. Beaty. 2001. Population Viability of Avian Endangered Species: The PVAvES Program, ERDC/CERL TR-01-7/ADA 388185. 
SAS I nstitute Inc. 1989, SAS/STAT User's Guide, Version 6, Fourth Edition, Volume 2, Cary, NC: SAS Institute Inc. 846 pp.

Schreiber, E.R. and M.A. Reed. 1999. Installation Summaries from the 1998 Survey of Threatened and Endangered Species on Army Lands. USA-CERL Technical Report 99/78/ADA 369718.

Stewart-Oaten, A., W. W. Murdoch, and S. J . Walde. 1995. "Estimation of temporal variability in populations." American Naturalist 146: 519-535.

SYSTAT. 1999. Version 9.01. SPSS Inc, Chicago, Illinois.

Watson, J. C., R. G. Hooper, D. L. Carlson, W. E. Taylor, and T. E. Milling. 1995. "Restoration of the Red-cockaded Woodpecker Population on the Francis Marion National Forest: Three Years Post Hugo," pp 172-182, in Kulhavy, D.L., R.G. Hooper, and R. Costa, Eds.,. Red-cockaded Woodpecker: Recovery, Ecology and Management. Center for Applied Studies in Forestry, Nacogdoches, Texas. 


\section{Appendix: PVAvES Input Data File}

Printout of the PVAvES formatted input data file, used in this study to parameterize all nine hypothetical disturbance scenarios. Parameter values denoted as "VARIED" differed among the scenarios, as shown in Table 20. All other parameter values were exactly the same for all scenarios.

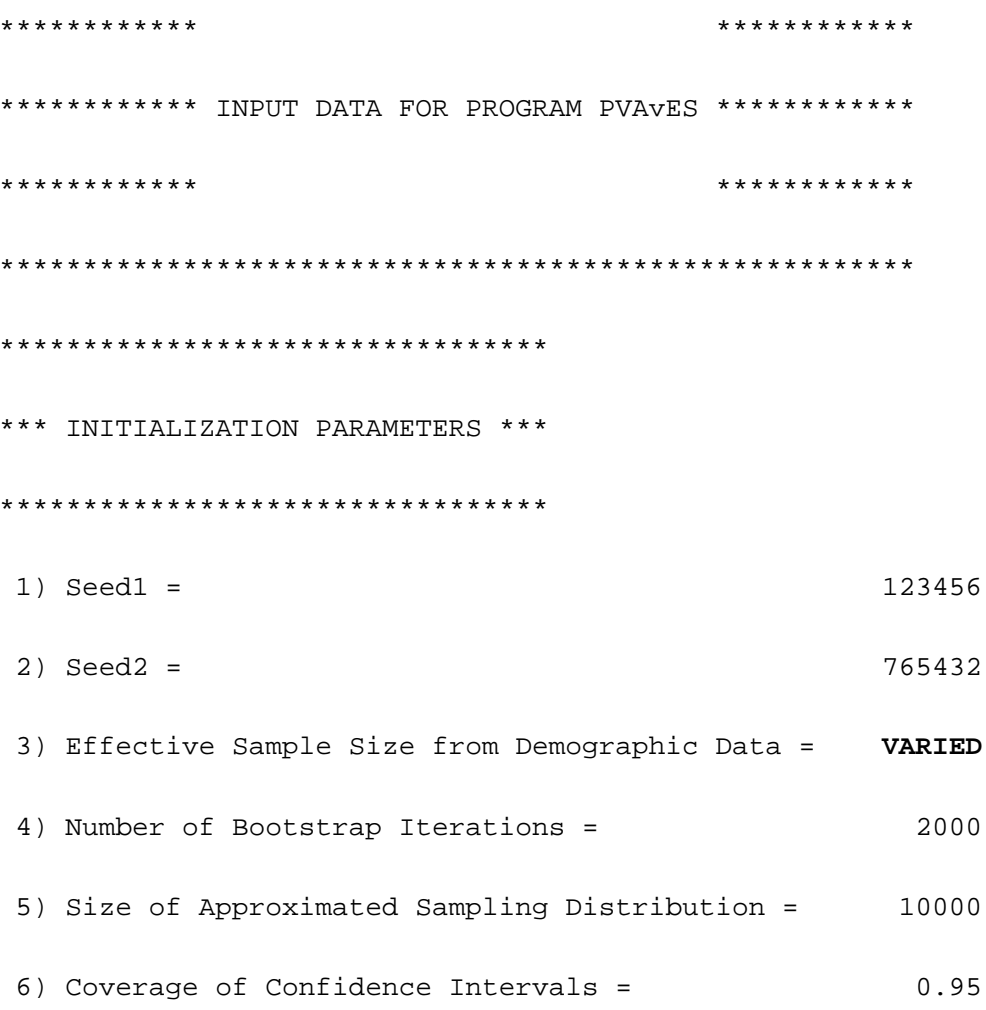

1) Seed1 $=$

2) Seed2 =

3) Effective Sample Size from Demographic Data =

VARIED

4) Number of Bootstrap Iterations =

5) Size of Approximated Sampling Distribution =

10000

6) Coverage of Confidence Intervals =

0.95

7) Initial population size =

(breeding females)

8) Maximum population carrying capacity = 
9) Extinction threshold =

10) Target population size after 100 years =

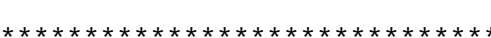

** DEMOGRAPHIC PARAMETERS ***
5

250

11) Mean proportion of successful nests =

VARIED

12) with temporal standard deviation =

VARIED

13) and sampling standard deviation $=$

VARIED

14) Mean seasonal fecundity of successful nests (fledglings of both sexes) = VARIED

15) with temporal standard deviation =

VARIED

16) and sampling standard deviation =

VARIED

17) Maximum possible seasonal fecundity =

4

(fledglings of both sexes)

18) Probability that a fledgling is female =

0.5

(based on fledgling sex ratio)

19) Mean fledgling female survival rate (to next breeding season) =

0.3901

20) with temporal standard deviation =

0.0000

21) and sampling standard deviation =

0.0624

22) Mean adult female annual survival rate =

0.7092

23) with temporal standard deviation =

0.0402

24) and sampling standard deviation =

0.0572

25) Immigration constant or stochastic (poisson)? =

(Enter 0 for CONSTANT, 1 for STOCHASTIC )

26) Mean immigration rate (breeding females per year) =

(must be an integer for CONSTANT immigration) 


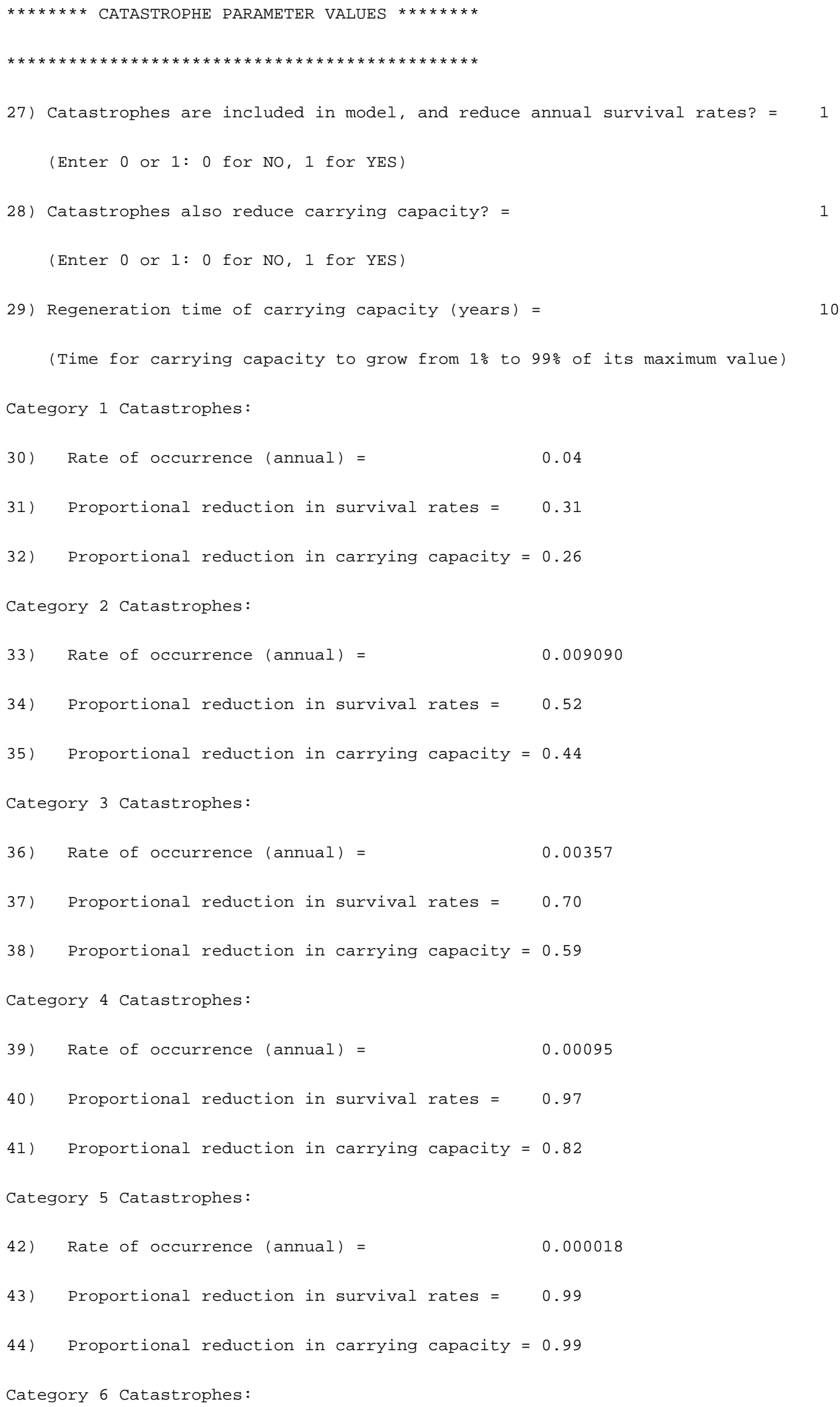




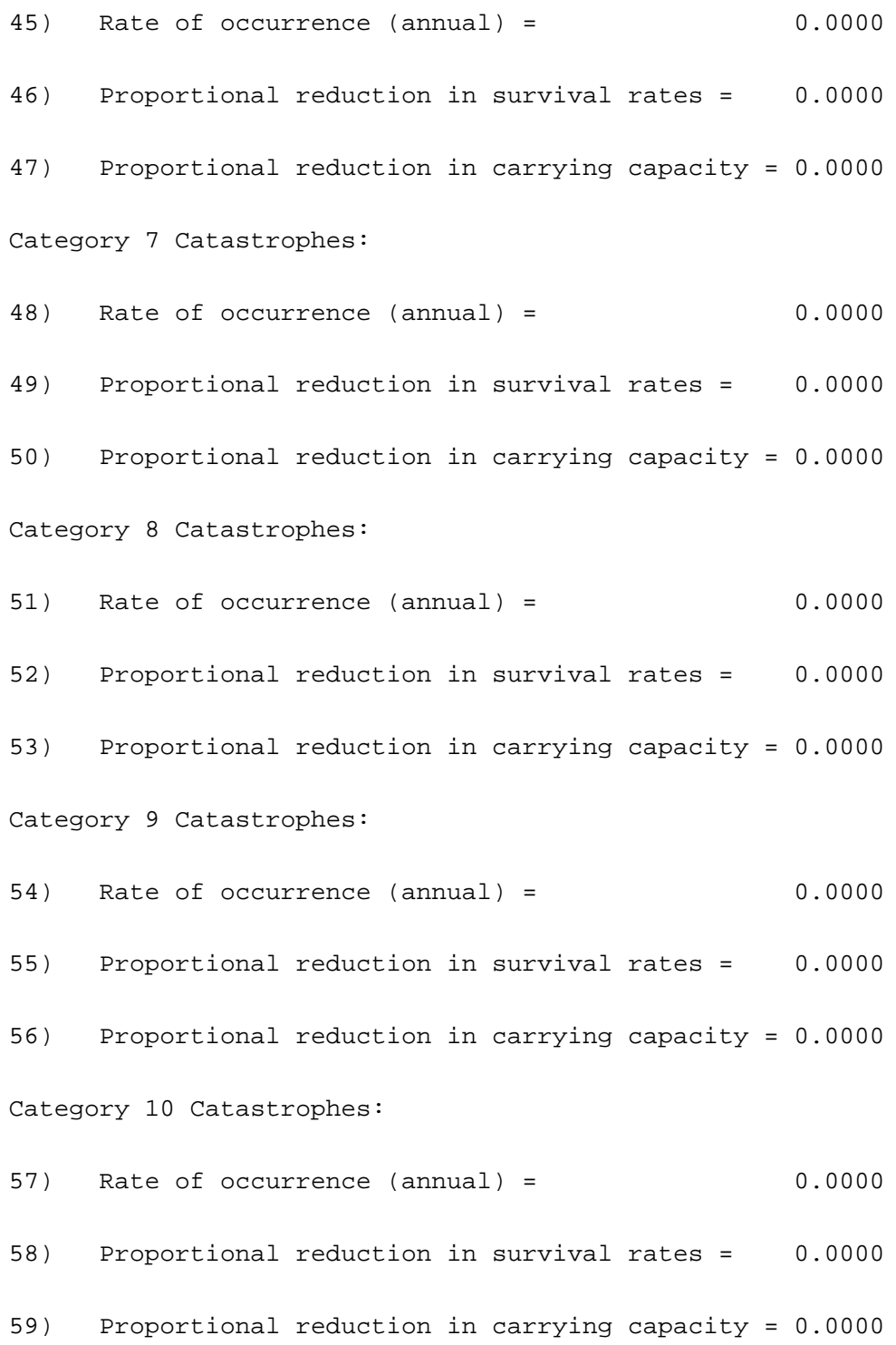




\section{CERL Distribution}

Chief of Engineers

ATTN: CEHEC-IM-LH (2)

DAIM-ED-N (2)

Engineer Research and Development Center (Libraries)

ATTN: ERDC, Vicksburg, MS

ATTN: Cold Regions Research, Hanover, NH

ATTN: Topographic Engineering Center, Alexandria, VA

U.S. Fish and Wildlife Service

Field Office, Clemson SC

Research Coordinator, Arlington, VA

Defense Tech Info Center 22304

ATTN: DTIC-O

10

$8 / 02$ 


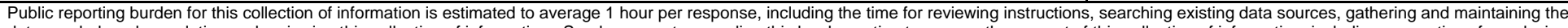

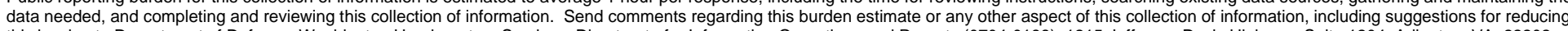

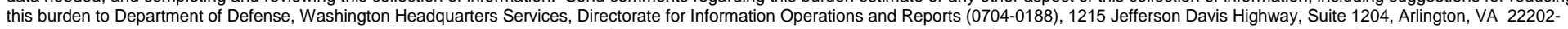

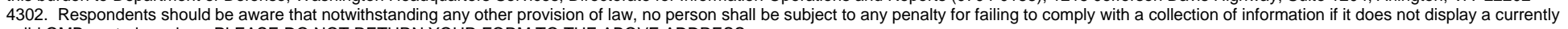
valid OMB control number. PLEASE DO NOT RETURN YOUR FORM TO THE ABOVE ADDRESS.
1. REPORT DATE (DD-MM-YYYY)
2. REPORT TYPE
3. DATES COVERED (From - To)

08-2002

4. TITLE AND SUBTITLE

Final

Assessment of Effects of Maneuver Training Activities on Red-cockaded Woodpecker

Populations on Fort Stewart, GA

5a. CONTRACT NUMBER

5b. GRANT NUMBER

5c. PROGRAM ELEMENT NUMBER

6. AUTHOR(S)

Timothy J Hayden, Robert H Melton, Beth Willis, L.B. Martin III, and Tim Beaty

\section{5d. PROJECT NUMBER}

622720A896

5e. TASK NUMBER

5f. WORK UNIT NUMBER

TD0

7. PERFORMING ORGANIZATION NAME(S) AND ADDRESS(ES)

U.S. Army Engineer Research and Development Center (ERDC)

8. PERFORMING ORGANIZATION REPORT

NUMBER

ERDC/CERL TR-02-17

Construction Engineering Research Laboratory (CERL)

P.O. Box 9005

Champaign, IL 61826-9005

\section{SPONSORING / MONITORING AGENCY NAME(S) AND ADDRESS(ES)}

Headquarters, Department of the Army

10. SPONSOR/MONITOR'S ACRONYM(S)

Office of the Director of Environmental

DAIM-ED-N

Programs

600 Army Pentagon

11. SPONSOR/MONITOR'S REPORT NUMBER(S)

Washington, DC 20310-0600

\section{DISTRIBUTION / AVAILABILITY STATEMENT}

Approved for public release; distribution is unlimited.

\section{SUPPLEMENTARY NOTES}

Copies are available from the National Technical Information Service, 5285 Port Royal Road, Springfield, VA 22161.

\section{ABSTRACT}

In Red-cockaded woodpeckers (RCWs), several factors have been identified that affect reproduction and cluster occupancy including both demographic and habitat parameters. This report analyzes potential training effects in relation to these other parameters; in fact, demographic factors were the best predictors of some aspects of RCW reproductive success and cluster occupancy. This result emphasizes the importance of installation managers being aware of the biological factors potentially limiting populations under their management concern and of tailoring monitoring plans to acquire the relevant data necessary to evaluate all potential sources of population limits. For installations implementing the Army 1996 "Management Guide-lines for the Red-cockaded Woodpecker on Army Installations" estimates of critical demography parameters will be available. However, based on data availability on Fort Stewart, special emphasis should be placed on follow-up monitoring of banded populations. Emphasis on intensive habitat data collection is probably not warranted if installations are adequately implementing pre-scribed burning and cavity augmentation programs. Data for Fort Stewart suggest that habitat is not an important factor in clusters with adequate midstory control and cavity availability.

\section{SUBJECT TERMS}

Red-cockaded woodpecker (RCW)

Fort Stewart

16. SECURITY CLASSIFICATION OF:

a. REPORT

Unclassified

Unclassified military training

endangered species environmental management

S

\begin{tabular}{|c|c|}
$\begin{array}{c}\text { 17. LIMITATION } \\
\text { OF ABSTRACT }\end{array}$ & $\begin{array}{c}\text { 18. NUMBER } \\
\text { OF PAGES }\end{array}$ \\
\cline { 2 - 2 } & 74 \\
\hline
\end{tabular}

19a. NAME OF RESPONSIBLE PERSON Timothy J Hayden

19b. TELEPHONE NUMBER (include area code)

(217) 352-6511 ext 6365 